\title{
The Relationship between Choice Co-Construction and Symbolic Play in Mother-Child Dyads
}

\author{
Lisa Michelle Noll \\ Loyola University Chicago
}

Follow this and additional works at: https://ecommons.luc.edu/luc_theses

Part of the Education Commons

\section{Recommended Citation}

Noll, Lisa Michelle, "The Relationship between Choice Co-Construction and Symbolic Play in Mother-Child Dyads" (1997). Master's Theses. 4264.

https://ecommons.luc.edu/luc_theses/4264

This Thesis is brought to you for free and open access by the Theses and Dissertations at Loyola eCommons. It has been accepted for inclusion in Master's Theses by an authorized administrator of Loyola eCommons. For more information, please contact ecommons@luc.edu. (c) $($ (i) $\Theta$

This work is licensed under a Creative Commons Attribution-Noncommercial-No Derivative Works 3.0 License. Copyright (C) 1997 Lisa Michelle Noll 
LOYOLA UNIVERSITY CHICAGO

THE RELATIONSHIP BETWEEN CHOICE CO-CONSTRUCTION AND SYMBOLIC PLAY IN MOTHER-CHILD DYADS

A THESIS SUBMITTED TO

THE FACULTY OF THE GRADUATE SCHOOL IN CANDIDACY FOR THE DEGREE OF

MASTER OF ARTS

DEPARTMENT OF COUNSELING PSYCHOLOGY

BY

LISA MICHELLE NOLL

CHICAGO, ILLINOIS

MAY 1997 
Copyright by Lisa Michelle Noll, 1997 All rights reserved. 


\section{ACKNOWLEDGEMENTS}

In preparing this master's thesis, I am indebted to my thesis committee: Dr. Carol Harding, Dr. Stephanie Stilson, and Dr. Lenore Weissmann for their continued guidance, perspective and support. I am especially thankful to Dr. Harding for serving as my thesis committee director, and for teaching me about the special interactive relationship that develops between a mother and a child. Dr. Stilson gave me a springboard from which my thesis and future research interests have developed, and has helped me decipher the meaning and importance of child's play. Dr. Weissmann's assistance and guidance with the procedural structure brought this thesis to life, and her knowledge gave me the foundation necessary from which I was able understand the developmental process. A special thanks goes to the Center for Children, Families, and Community for assisting me with subject recruitment and data collection. From this team, I am especially thankful to Kerry Brown and Chris Payne for assisting me with reliability measures. I also wish to thank

Dr. Jack Kavanagh for helping me both analyze and interpret my statistical findings. To the mothers and children that participated in this study, I thank them for their participation, and for sharing their special relationship with me through play. Throughout this process I have been encouraged and supported by my family, friends, colleagues, and co-workers. To them all I am deeply grateful. 


\section{CONTENTS}

ACKNOWLEDGEMENTS........................................................ii

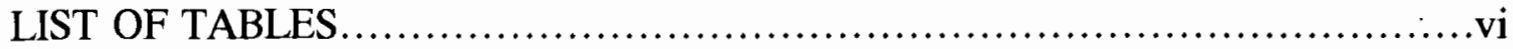

LIST OF ILLUSTRATIONS............................................... vii

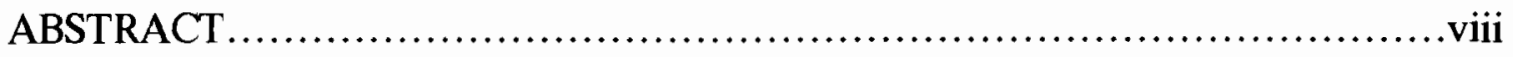

Chapter

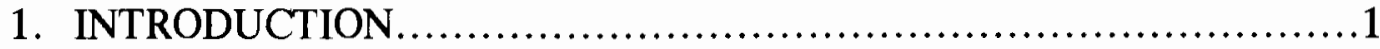

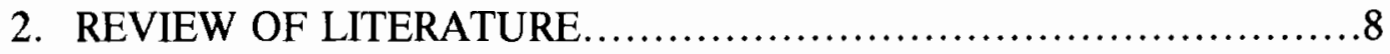

Divergent and Convergent Thinking $\ldots \ldots \ldots \ldots \ldots \ldots \ldots \ldots \ldots \ldots \ldots . \ldots \ldots$

Symbolic Play .................................................. 10

Cognitive Style.............................................. 15

Nature of Mutual Regulation in Mother-Child Relationships..........19

Summary of Research Intent..................................25

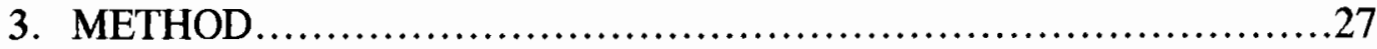

Subjects.....................................................

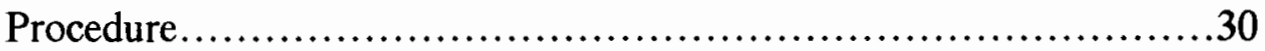

Videotaping of Mother-Child Dyads.............................30

Coding Scheme for Choice Co-Construction.....................31

Coding Scheme for Nonsymbolic and Symbolic Play..............35

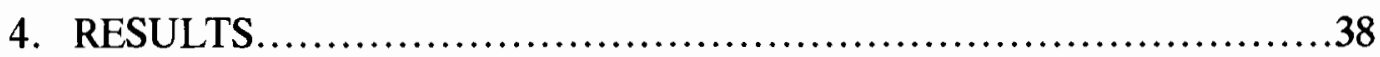

Hypothesis...................................................

Nonsymbolic Play versus Options-Promoting and OptionsLimiting.....................................................39 
Symbolic Play related to Options-Promoting and Options-

5. DISCUSSION.

Hypothesis Testing...............................................50

Conclusion......................................................68

Appendix

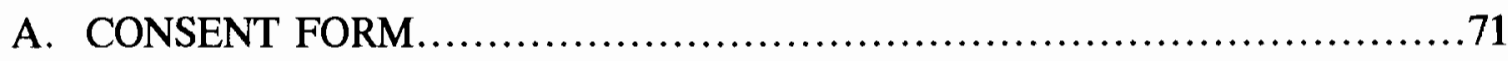

B. CHOICE CONSTRUCTIONS: DESCRIPTIONS AND CODING

DEFINITIONS.......................................................... 74

C. OBLIGATION CHOICE CO-CONSTRUCTION CODING

EXAMPLES...................................................... 77

D. TODDLER PLAY LEVELS CODING EXAMPLES........................80

E. TODDLER PLAY LEVELS CODING FORM $\ldots \ldots \ldots \ldots \ldots \ldots \ldots \ldots \ldots \ldots . \ldots . \ldots \ldots$

F. SYMBOLIC PLAY AND OBLIGATION CHOICE

CO-CONSTRUCTION SUMMARY SHEET $\ldots \ldots \ldots \ldots \ldots \ldots \ldots \ldots \ldots \ldots \ldots . \ldots 6$

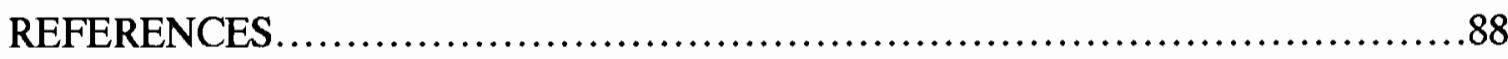

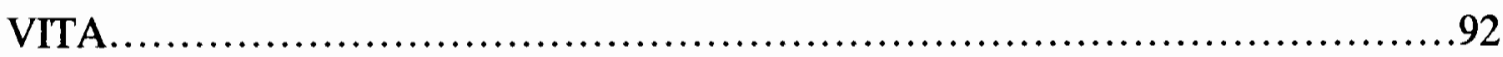




\section{TABLES}

Table

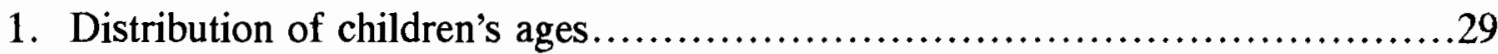

2. Toddler Play Levels........................................................

3. Correlation Coefficients for Symbolic and Nonsymbolic Play with Options-Promoting and Options-Limiting

4. Multiple Regression Equations for Nonsymbolic and Symbolic Play with Options-Promoting and Options-Limiting as Variables.

5. Means and Standard Deviations of Symbolic and Nonsymbolic Play, Options-Promoting and Options-Limiting....

6. Options-Promoting and Options-Limiting as Variables in the Significant Multiple Regression Equation for Symbolic Play .48

7. Correlation Coefficients and Multiple Regression Equations for Symbolic and Nonsymbolic Play with Child's Age 53

8. Means, Standard Deviations, and Correlation Coefficients of Demonstrations and Affirmations by Symbolic Play

9. Multiple Regression Equation for Demonstrations and Affirmations within Symbolic Play

10. Means and Standard Deviations of Symbolic Play,

Nonsymbolic Play, Options-Promoting, and

Options-Limiting by Age Groups. 


\section{ILLUSTRATIONS}

Figure

1. Choice Co-Construction Interactive Behaviors coded for

150 2-second intervals for each mother-child dyad.

2. Average Frequency Distribution of Option-Promoting and

Options-Limiting by Nonsymbolic Play....

3. Average Frequency Distribution of Options-Promoting and

Options-Limiting by Symbolic Play

4. Average Frequency Distribution of Demonstrations and

Affirmations by Symbolic Play .60

5. Frequency Distribution of Symbolic Play by Age Groups.....................62

6. Frequency Distribution of Nonsymbolic Play by Age Groups..................65

7. Frequency Distribution of Options-Promoting by Age Groups.................66

8. Frequency Distribution of Options-Limiting by Age Groups..................67 


\begin{abstract}
In a cross-sectional investigation, the extent to which the mother-child interactive relationship either promotes or limits a child's ability to see choices in the environment was measured. The level and frequency of symbolic and nonsymbolic play in 30 children, ages 12 - to 47 -months was coded and mothers' options-promoting and options-limiting behaviors were summed. It was found that children whose mothers created an options-promoting social context spent more time engaging in symbolic play. Nonsymbolic play was not found to be significantly influenced by the mother's behaviors as either options-promoting or options-limiting. The analyses suggest that a child's cognitive development, as measured by engagement is symbolic play, is influenced by the social context created by the mother's options-promoting interactive style.
\end{abstract}




\section{CHAPTER 1}

\section{INTRODUCTION}

Jennifer, a 40-month old, and her mother, were having a tea party. When Jennifer set the table for the party, she gave herself a blue cup and green saucer, and her mother a yellow cup and blue saucer. Jennifer poured the tea and ate "pretend" cookies that were really yellow Legos. Jennifer's mother praised Jennifer for making such good tea and cookies. As Jennifer drank her tea, her mother picked up the doll, sat her next to Jennifer, and asked Jennifer to give the baby her bottle because she looked hungry. Jennifer picked up the baby, gave her the bottle, then gave her a kiss and a hug.

Linda, a 39-month old, and her mother were also having a tea party. As Linda passed out the plates, Linda's mother rearranged her table setting so that each cup and saucer matched in color. Linda poured the tea for her and her mother. Linda's mother drank her tea with gurgling noises, and asked for more tea with sugar. When Linda went to spoon out the "pretend" sugar, Linda's mother corrected her choice of the sugar bowl and pointed out the correct sugar bowl for Linda to use.

While both Jennifer and Linda were having tea parties with their mothers,

these tea parties were very different. What made Jennifer think of substituting Legos for cookies, whereas Linda did not? Why was Jennifer's mother not bothered by the mismatched cups and saucers, while Linda's mother was? Can the difference between the two parties be accounted for by the different ways that the two mothers interacted with their daughters, or was it something about the daughters' individual make-up that made them play differently? Or is the interactive relationship between the mother and child being influenced by a combination of the child's factors and the mother's 
factors?

In order to examine what is influencing the differences that are identified in these mother-child dyadic play interactions, both partners' behaviors must be considered within the dyadic interaction (McCune, Dipane, Fireoved, \& Fleck, 1994). Thus, the maternal behaviors that a mother adopts may be influenced by the child's characteristics, which in combination, may come to produce a particular interactive style. Conversely, the developmental strides that a child makes both influences and is influenced by the style and the content of the mother-child interaction.

Several researchers have looked specifically at the interactive play relationship that develops between parents and their children, and the subsequent effect that the parenting style that is adopted has on the child's cognitive development (Levine, 1988; MacDonald \& Parke, 1984; McCune et al., 1994; O’Connell \& Bretherton, 1984; Tamis-LeMonda \& Bornstein, 1991, 1990; Slade, 1987a, 1987b; Werner \& Kaplan, 1963). These researchers have investigated the maternal qualities of language effectiveness, skill-related behaviors, play behaviors, activity level, stimulation, and affect.

One way a child's cognitive abilities can be represented is through the child's symbolic play (Piaget, 1962). Symbolic play illustrates a child's ability to represent an absent person or object through words, gestures, imitations, substitutions, and associations from experiences in daily life. Piaget (1962) proposed that the child's level, or ability to engage in symbolic play, can be viewed as providing a measurement of the child's symbolic representational capacity (Bretherton, 1984). He 
noted symbolic representation to emerge near the age of 13-months and culminate during the preschool years. Levine (1988) viewed play as the one aspect of the parent-child relationship that contributes directly to the child's emotional, social and cognitive development.

Vygotsky (1978) proposed that children learn concepts while engaged in social interactions. His theory emphasizes the significant role that a child's social influences have on the development of cognitive abilities. Thus, a child's social relationships, or exchanges, are thought to guide a child's mental processes until the child is able to conceptualize them independently, or to internalize them. Much of the research in the area of cognitive development in children is based on Vygotsky's theory.

Harding et al.'s (Harding, Weissmann, Kromelow, \& Stilson, in press; Harding, Stilson, \& Moison, 1996; Harding, Kromelow, Stilson, \& Touris, 1995; Harding, 1987, 1985, 1982) Choice Construction model, based in part on Vygotsky's theory, proposes that special behaviors initiated by a mother are identified as either facilitating or inhibiting a child's ability to make choices for his or her own behavior. She labeled these interactive behaviors between a mother and a child as "choice coconstructions" and distinguished between these behaviors by placing them in three categories: 'sharing attention, rituals or stipulated behaviors, and obligations' (Harding et al., in press). As Stilson (1993) discussed, whether or not this maternal style encourages a thinking style within the child that develops throughout the child's lifetime, remains unclear. In looking at Harding's Choice Construction Model, Stilson (1993) questioned the extent to which the social context, or choice co- 
construction behaviors that the mother engages in, actually limits or promotes the development of a distinct thinking style in children that is consistent throughout development. Thus, according to Vygotsky, if a child were to internalize the social environment that encouraged the development of a cognitive style that allows the child to make choices for future behaviors, then the child may develop a divergent thinking style over time. Stilson and Harding (in press) and Stilson (1993) proposed that an "options-promoting" environment would help the child to see options available, or in other words, begin to develop a divergent thinking style.

In Stilson and Harding (in press) and Stilson's (1993) study, the mother-child behaviors in Harding et al.'s (1995) obligation choice co-constructions, were categorized as either "options-promoting" or "options-limiting." Affirmations and demonstrations by the mother were said to be options-promoting behaviors, while corrections and object replacements were viewed as options-limiting. Stilson found that symbolic play was related to an options-promoting social environment for 18month olds. The concurrent relationship between options-promoting interactive behaviors and symbolic play supports that these specific mother-child behaviors are related to symbolic cognitive abilities in children. These symbolic cognitive abilities are manifested as divergent and/or convergent thinking styles. Stilson (1993) proposes that predictive relationships between symbolic play and options-promoting interactive behaviors suggest that the child's symbolic play may temporally precede the interactive style adopted by the mother-child dyad.

Although these exploratory findings are provocative, the question remains as to 
the extent the mother-child interactive relationship promotes or limits choices and the frequency and level of related symbolic or nonsymbolic play that a child engages in. This thesis hypothesizes that mother-child interactions that promote options through the mother's use of affirmations and demonstrations will be related to children spending more time engaging in symbolic play, whereas options-limiting behaviors of corrections and object replacements will be related to children spending more time engaging in nonsymbolic play.

Specifically, this thesis is in part a replication and an elaboration of the longitudinal research procedure conducted by Stilson (1993) and targets her findings related to symbolic play and obligation choice co-constructions (Harding et al., in press, 1996, 1995). A cross-sectional design was employed to investigate the way in which children cognitively develop and the role that their social environment, specifically maternal interaction, plays in that development. Structured and free play mother-child interactions were videotaped. In order to examine the proposed relationship between symbolic play and options-promoting behaviors across the developmental period when symbolic representational capabilities are said to be emerging (Piaget, 1962), children from 12- to 47-months of age were studied. From the videotapes, the mother's obligation choice co-construction was coded as either options-promoting or options-limiting, and the child's level and frequency of play was coded as either symbolic or nonsymbolic.

It was hypothesized that the mother's interactive style as options-promoting or options-limiting would be correlated with a child's cognitive development, 
characterized by symbolic and nonsymbolic play. Children who engaged in higher levels and frequencies of symbolic play were predicted to be exposed to a mother who frequently interacted with the child within an options-promoting social context. Conversely, children who engaged in higher levels and frequencies of nonsymbolic play were predicted to be within the social context of a mother who primarily interacted with the child within an options-limiting context. For purposes of statistical analyses, symbolic and nonsymbolic play are the criterion variables and optionspromoting and options-limiting are the predictor variables.

Significant findings will suggest the reciprocal nature of the mother-child relationship and the important role that both partners play in fostering the development of the child's cognitive abilities. The predicted relationship between optionspromoting interactive behaviors and symbolic play is believed to support the idea that these mother-child behaviors relate to the cognitive development of a child. As Stilson (1993) referenced, future research could develop research designs to examine the extent to which divergent and convergent thinking styles develop, as predicted by the mother's interactive style, as it relates to the child's level and frequency of representational play. In addition, significant findings give clinicians another means by which intervention within the interactive relationship between mother-child/parentchild can be directed. If a clinician is able to assist parents in adopting an optionspromoting interactive style, then it may be possible not only to enhance a child's cognitive development, but to set the stage for a divergent thinking style to emerge. Investigating the way in which children cognitively develop, as measured by 
symbolic play, and the role that their social environment, facilitated by maternal interaction, serves, adds further support to the importance of the interactive relationship between a mother and a child in predicting characteristics of the child's present and future cognitive development. 


\section{CHAPTER 2 \\ REVIEW OF LITERATURE}

Nicolich (1977) proposed that play be viewed as a window for measuring the social development and cognitive maturity of a child. Observing child's play, from a cognitive perspective, allows researchers to infer the child's developing abilities to both engage in internal representation and to manipulate objects in pretend sequences. Symbolic play has been noted by Nowak-Fabrykowski (1994) to serve seven functions in the child's developmental process: cognitive, creative, ordering, stimulative, socializing, expressive, and substitutive. Findings support the notion that a child's symbolic play is a measure of cognitive development (see Bretherton, 1984; TrawickSmith, 1990; Werner \& Kaplan, 1963) and is influenced by the social environment -specifically the mother-child interaction (see Slade, 1987a, 1987b; Tamis-LeMonda \& Bornstein, 1991). Further, symbolic play is an indication of the child's creative capacity, or thinking style (see Nowak-Fabrykowski, 1994, 1992; Rosenberg, 1968; Trawick-Smith, 1990).

Stilson (1993) proposed a model where symbolic play serves as the construct to link early mother-child interactive behaviors and these later cognitive thinking styles (e.g., divergent and convergent thinking). This thesis was designed in an effort to provide further support for the association between specific mother-child behaviors 
and symbolic play. Research in the areas of symbolic play, cognitive style, and mother-child relationships (e.g., the maternal social context), will be discussed as they relate to the overall emergence of creative fluency in the form of a divergent/convergent thinking style, as proposed by Stilson's theoretical model.

"Symbolic play serves as the construct to link early mother-child interactive behaviors and the cognitive thinking styles [that develop over time]" (Stilson, 1993, p. 5). This relationship between cognitive styles, symbolic play as a measure of cognition, and social interaction is explored and discussed in the current study.

\section{Divergent and Convergent Thinking}

Much research in the area of cognitive styles in children has focused on its relationship with symbolic play (Dansky, 1980; Dansky \& Silverman, 1973; Lieberman, 1965). Overall, these studies find that children's symbolic play is related to divergent thinking measures, and they are based on the notion that creativity is rooted in symbolization (Nowak-Fabrykowski, 1992). The nature of play allows children to be creative; for children are able to generate play from objects and ideas in their world of experience. The connection between Vygotsky (1978) and creativity is that he believed individuals interact in the world based on their own symbolic representations of reality, whereas Piaget (1962) believed "symbolic assimilation [to be] a source of creative imagination" (p. 155).

Dansky and Silverman (1973) examined the differential outcomes of playful and imitative activity which are predicted by Piaget's (1962) theory, in which play involves a relaxation of efforts to adapt to reality, and imitation is viewed as 
hyperadaptive. Children, ranging in age from 4 to 6 years, were placed in one of three groups: play, imitating and control. In the "play" group, the children played with a determined set of objects; the "imitation" group engaged in an equivalent amount of imitative behaviors that the experimenter modeled with the same objects; and the "control" group engaged in a 'neutral' experience that did not involve those objects. Following the sessions, each subject was given an alternate-uses test, where the child was presented with one of the objects and asked to demonstrate how many different ways the object could be used.

Their findings were consistent with Piaget's views that when a child engages in imitative behavior, or accommodates to environmental demands, the child is thus limited in his opportunity to generated novel associations. It is when the child is able to relax his efforts to accommodate to reality that he is able to form new relationships and associations among objects, ideas, and actions. Creative thinking emerges when the child is able to generate large numbers of unusual associations that are unrelated to less freely assimilative thought. Thus, their results support the hypothesis that symbolic play facilitates associative fluency or divergent thinking.

\section{Symbolic Play}

O'Connell and Bretherton (1984) cite that Piaget viewed the child as an architect building his knowledge about the world. This knowledge is a result of the child's daily interaction within the structure of the world. In order for new cognitive structures to emerge, Piaget (1962) suggested that the child must reach a state of disequilibrium. In this state, the child's cognitive structures for interacting in the 
world are confronted by new situations, for which the current cognitive structures cannot be applied (O'Connell \& Bretherton, 1984). Prior to this point, the cognitive structures guide the child's interactions in the world, until they are challenged by a new situation.

According to Piaget (1962), the creation of symbols is divided into stages during the child's developmental process. Symbols emerge when a child is able to imitate an object or behavior that is not seen. This imitation thus results in symbolic thoughts. A child's play behaviors are believed to serve as an index of the child's representational capacity (Piaget, 1962). Piaget cited symbolic representation as emerging around the age of 13-months and culminating during the preschool years.

This change in play is characterized by the way in which children manipulate the symbolic representation of objects and situations, and recreate events (NowakFabrykowski, 1994). Early symbolic play is characterized by children moving from self-directed pretenses (e.g., drinking from a cup), to other-directed pretenses (e.g., giving a doll a drink), to engaging with multiple number of pretenses (e.g., having two dolls talk with one another), to finally substituting pretenses (e.g., substituting Legos for cookies). According to Kagan (1983), when the child makes the shift to other-directed and then more sophisticated play, it suggests that the child is now directing play rather than engaging in sensorimotor play (e.g., moving a car around on the floor). Symbolic play is thus the child's ability to represent an absent person or object through words, gestures, and sounds.

Research in the area of symbolic play has primarily focused on Piaget's theory 
of symbolic play as an index of cognitive development (Bretherton, 1984; Lowe, 1975; McCune-Nicolich, 1981; Trawick-Smith, 1990; Werner \& Kaplan, 1963). Trawick-Smith (1990) examined the ways in which preschoolers' play differed when they were presented realistic versus nonrealistic toys. His findings concluded that realistic play props were the preferred medium for representational play. The significance of this finding is that when the children played with realistic toys, their creativity increased, thus increasing their capability to engage in representational play. Like Trawick-Smith (1990), other researchers in the area of symbolic play have used more realistic than nonrealistic toys in their studies (Tamis-LeMonda \& Bornstein, 1994, 1991, 1990; Slade, 1987). Based on the significant findings in these studies, the mother-child dyads in this study were presented with a realistic toy selection.

Another point of interest in the symbolic play literature is the finding by Werner and Kaplan (1963). They found that there is a relationship between the sharing of meaning with another and the emergence of representational symbols. This finding suggests that the child's play partner has a role in the types of play activities that the child engages in, and may even contribute to the representational abilities that a child displays in play.

The idea of studying the relationship between symbolic play and cognition in the presence of a mother appears to be grounded in the notion that play allows mother and child to interact closely with one another and in the absence of any power differentials. The presence of an experienced symbolic player, the mother, would appear to add support to the child as a novice symbolic player, and thus assist the 
child by allowing the child to be the director of play (Fiese, 1990). Many researchers have added support to the idea that the maternal presence either facilitates or promotes the emergence of symbolic play in children (see Fiese, 1990; Slade, 1987a, 1987b; Tamis-LeMonda \& Bornstein, 1991).

Fiese (1990) looked at the difference in play levels for toddlers, between the ages of 15-24-months, when they played alone, with their mother, and in an activity modeling the mother. She found that children engaged in more complex forms of play when they played with their mother versus when they played alone. It was found that maternal intrusions, or the mother's interruptions into the child's play, were negatively related to symbolic play and were more likely to precede more sensorimotor forms of play. Conversely, turn-taking was more likely to precede symbolic play. This finding suggested that while the nature of pretend play is that it is an exchange with partners that take-turns, this process with the mother appeared to facilitate play. Thus, Fiese (1990) proposed that symbolic play should be measured, not only with respect to the child's own cognitive growth, but also with the influence of the mother which allows for interpersonal achievement.

Slade (1987a, 1987b) conducted two experiments which focused on the understanding of the role that the social context, or the presence of caregivers, has in the emergence of symbolic representation in children. Slade (1987b), in a longitudinal study looking at children from 20 -to 28 -months, examined the role that the mother's involvement had on the child's development of symbolic play. She found that symbolic episodes became more complex with increasing age, and the level of make- 
believe play increased when the mother was "available." It was when the mother both initiated and actively interacted with the child that the child's engagement in makebelieve play increased. These findings suggest that when the child is able to interact with another individual, the child's symbolic representation will not only be higher, but will also be more elaborate in context. While Slade (1987b) proposed that the mother's involvement and interaction with the child serves an important role has in the child's developing symbolic abilities, it left open the influence that the mother's own individual social way of interacting with the child has on those emerging abilities.

Tamis-LeMonda and Bornstein (1991), in a longitudinal investigation, looked at the individual differences and developmental changes in mother and toddler nonsymbolic and symbolic play when children were $13-$ and 20 -months of age. They found that the symbolic play sophistication between mothers and toddlers changed in similar ways. The identified differences within each child and across the two age groups are proposed to be partly mediated by the mother, or partner, and partly mediated by the child's own processes. As interpreted by Piaget (1954) these child processes are related to symbolic representation as part of cognitive development. Mothers who engaged in more symbolic play were found to have children who engaged in more symbolic play, both as a result of spontaneous acts and following the mother's encouragement. It appears from this finding that there may be some other source, possibly the mother's social context, that is contributing to, or influencing the child's later symbolic play sophistication. Tamis-LeMonda and Bornstein (1991) propose that these factors influencing toddler symbolic play may be accounted for by 
the mother's affect, the mother's activity level, or the amount of stimulation they provide in their child's play. This implies that when mothers and children engage with one another, each brings their own individual characteristics which may ultimately effect the way in which they both respond to and reinforce one another. While the research by Fiese (1990), Slade (1987b), and Tamis-LeMonda and Bornstein (1991) was designed to investigate the relationship between the mother's presence and the child's engagement in symbolic activities, they all note the significant role that the child's underlying cognitive abilities have in the development of symbolic play.

\section{Cognitive Style}

While Piaget (1962) has linked the development of representational skills to the internal changes occurring within the child's cognitive structures, Vygotsky (1978) places the emphasis on the social interaction that the child has in the world as influencing the changes in cognition (O’Connell \& Bretherton, 1984). Vygotsky (1978) argues that make-believe substitution of one object for another contributes to the development of representational capabilities in children. The development of symbolism is thus characterized by the child's movement away from interacting according to objects present within the child's perceptual world, to interacting according to actions that are generated by ideas.

As Elder and Pederson (1978) discuss, symbolic play signifies the child's ability to let go of the ideas that place definitions on objects (e.g., a stick is a stick and only a stick) and is able to separate the meaning from the real object (e.g., a 
spoon) to allow the stick to represent a spoon. Vygotsky (1978) proposed that when children engage in symbolic play, they are engaging in substitution, by first substituting one objects for another object that appears to be similar in some context, and later pretending without any object present. When the child is able to pretend in the absence of an object, the child is exhibiting an important shift away from being tied to the thoughts and ideas about objects in the child's immediate environment toward true symbolic representation.

For Vygotsky (1978), there was a distinction between what children could do on their own and what they could do with adult scaffolding, or assistance. A child is said to be in the zone of proximal development or "the distance between the actual development level as determined by independent problem solving and the level of potential development as determined through problem solving under adult guidance or in collaboration with more capable peers" (Vygotsky, 1978, p. 86). As Small (1990) discusses, when a mother scaffolds (Bruner, 1975), she makes the message redundant by repeating it several times (Small, 1990, p. 411). This is followed by pauses in the scaffolding, which give the child an opportunity to contribute to the exchange. If the child continues to require assistance, the mother can continue to scaffold until the child is able to become fully engaged. Scaffolding is thus gradually withdrawn as the child's cognitive skills become more sophisticated and less assistance is needed.

Researchers in the area of child cognitive development have been influenced by Vygotsky's (1978) theory and have thus measured cognitive development as being measured by the child's symbolic play, and influenced by the mother-child didactic 
relationship.

Kreye (1984) looked at how children's play, during the ages of 24 to 48 months can be used to elicit conceptual skills. The toys used in Kreye's study were all interpreted to be familiar objects to the child, for the child's conceptions would be based on meanings assigned to familiar objects. Mothers were instructed to create a context before the child started to play and to continue with this display until the mother was certain that the child understood the context. Her findings suggest that mothers and children would at times refer to past experiences with a particular object, which appeared to facilitate their involvement with that object. The mothers were found to structure the play in such a way that allowed the children to expand their current cognitive structures. The strength of the interrelatedness within the motherchild interaction was identified when the child sought out the mother's guidance when it was needed. These findings support Vygotsky's (1978) theory that mothers' interactions may facilitate the development of the child's cognitive structures. This further suggests the interpretative role that mothers play in terms of being able to identify when their children require assistance and when they should be given space to expand upon the context provided. Thus, the questions remains: If the mother is unable to judge her child's understanding appropriately, or the mother fails to provide a context which the child can grasp on to, what will the child's symbolic play (or cognitive structures) look like?

Tamis-LeMonda and Bornstein (1994) explored the specificities in language play association when children were 13 and 20 -months old, while simultaneously 
considering the mother's referential language and symbolic play. They assessed the child's play competence, maternal language stimulation, and maternal play stimulation. Their findings suggest that the child's cognition, measured by play competence, and the maternal influence were each multidimensional. Thus, the relationship between language-cognition is not solely influenced by maternal language and play. These findings add support to the hypothesis that individual characteristics in the emergence of language and symbolic play may reflect the child's varying capabilities to understand and express experiences through language and symbolic representation.

Much research has been conducted which supports the notion that the link between a child's developing cognitive abilities is in part influenced by the maternal relationship, and in part a result of the child's own cognitive structures (Bornstein, Vibbert, Tal, \& O’Donnell, 1992; Bruner, 1975; Kreye, 1984; Tamis-LeMonda \& Bornstein, 1994, 1990; Zukow, 1980). From these studies, questions have emerged as to the influence that the mother's characteristics have on the relationship that develops between the mother and child. This is of importance since many researchers have already noted the influence that a maternal presence has in relation to a child's representational capabilities. Determining what maternal characteristics either facilitate or inhibit the child's cognitive capabilities, and the overall effect that this will have on the child's ability to form new cognitive structures, has implications both in the didactic relationship between a mother and child, and the child's overall future cognitive abilities. 


\section{Nature of Mutual Regulation in Mother-Child Relationships}

Levine (1988) interprets Vygotsky's (1978) notion of parental scaffolding as the parents' abilities to help the child translate personal expression into familiar shared symbols. She proposes that the differences in parent-child play may reflect individual differences in parenting style, which subsequently impact the child's subsequent emotional, social and cognitive development. By modeling and instructing, parents appear to assist the child in acquiring the social knowledge necessary to depict sociodramatic roles. She suggests that the parents act as an audience and thus may facilitate the child's motivation to engage in symbolic representation ( $\mathrm{O}^{\prime} \mathrm{Connell} \&$ Bretherton, 1984; Dunn \& Wooding, 1977; Slade, 1987b; Werner \& Kaplan, 1963).

Clarke-Stewart (1973) in her longitudinal study of infants from 9- and 18months of age, found that the child's overall level of symbolic play was related to the mother's effectiveness, positive and responsive language, and the amount of interaction with the child. The mother's verbal stimulation was found to be the most highly correlated with the child's competence in symbolic play. Maternal effectiveness had a positive relationship with the child's early test performance, and was negatively related to the child's irritability. These findings suggest that in terms of developmental outcomes, children appear to engage in the highest levels of symbolic play possible for them according to their capabilities when they are engaged with a mother who is both highly responsive and stimulating to the child.

O'Connell and Bretherton (1984) sought to assess the nature of mother-child interaction, when the mother was first passive and then an active participant. Their 
findings revealed that when children were 20 and 28 -months old, the variation within the childrens' play increased, as a function of the child's age, when the mother was actively playing with her child. Specifically, the mothers who had an interactive style that included demonstrations and suggestions were found to directly influence the child's subsequent symbolic play behaviors. It is thus not sufficient to merely be "present" with the child to influence development. This finding provided additional support to the notion that it is the mother's active guidance, rather than her passive presence, which contributes to the multidimensional view of the mother-child relationship (see Slade, 1987b). The individual differences among the children with "active" mothers was proposed to be a result of the child's own decision making process which determines which maternal instructions will be acted upon.

McCune et al. (1994) explored the character of mutual regulation during play by describing trends and examining individual differences in a longitudinal sample of $9,12,18$, and 24 -month olds. They found that toddlers, at 24-months, had the least amount of contingency responding (or joint focus) with their mothers, were the least verbal, and produced the lowest frequency of symbolic play behaviors. They concluded that play behaviors are mutually regulated between both mother and child. The idea that both partners play a significant role in the regulation of their interaction with one another suggests that both partners not only shape the play that emerges, but also influence the level of responsiveness that is generated.

These three studies provide further evidence that what appears to contribute to the developing cognitive abilities in a child is in part the child's own capabilities, and 
the passive or active role that the mother plays in her interactions with her child. This notion that the mother provides directives for symbolic play, which the child then acts upon, suggests that the mother's directives are providing options for the child. From the options available, the child must decide to either follow the familiar cognitive structures, or to form new ones based on the options provided by the mother.

The literature reviewed provides evidence that suggests that the social context in which a child develops influences the child's symbolic play, and subsequent cognitive development. Stilson (1993) points out that when that child is the most influenced by their social context is uncertain. With respect to Vygotsky's (1978) theory, he based the child's representational capabilities to be experienced in the context of social interchange, but the role that social interactions have on the child's developing cognitive processes is unclear (Stilson, 1993). She questions "whether social interactions influence and guide an internal thinking process that already exists in the child's mind -- or, whether social interactions actually form and create the thinking process" (Stilson, 1993, p. 18). Stilson (1993) interpreted Vygotsky's theory to suggest that the social context of the child influences the cognitive structures that already exist within the child. According to this interpretation, within the child's social context, the mother brings specific ideas to the child as a way of guiding the child's understanding of behaviors and actions. The mother frames these ideas in a context of play, which allows her to demonstrate these ideas to her child. The child, unlike a sponge, does not ingest all of these ideas, but rather it is the child who forms his/her own meaning from what the mother has demonstrated. On a simplistic level, 
the mother could demonstrate how the child should interact with a particular toy, while the child could conceptualize his/her own way of playing. Thus, the child can be seen as adopting a play behavior from several choices presented by the child's mother, or social context. From this interpretation, Stilson (1993) questioned whether or not the emergence of divergent and convergent thinking followed a developmental course, influenced by the dyadic behaviors which either promote or inhibit a child's ability to see choices in his environment. Some dyadic behaviors could be hypothesized to be options-promoting or similar to a divergent thinking style, while other behaviors could be hypothesized to be options-limiting or similar to a convergent thinking style (Stilson, 1993).

Harding et al.'s (in press, 1996, 1995, 1987, 1985, 1984, 1982) Choice Construction Model, based in part on Vygotsky's theory, proposes special behaviors initiated by a mother that are identified as either facilitating or inhibiting a child's ability to make choices for his own behavior. These interactive behaviors between a mother and child are labeled "choice co-constructions" because they allow the mother and child to co-construct their behaviors with one another that then facilitate the child's first decision-making abilities (Harding \& Moisan, 1987). The choice coconstruction behaviors are labeled as follows: 'sharing attention, rituals or stipulated behaviors, and obligations" (Harding et al., in press).

For the purposes of this study, the role of shared attention and obligation choice co-constructions will be discussed. In order for an adult to structure any event with a child, shared attention is necessary. When both the child and the adult are 
engaging in shared attention, it allows the child to see all of the options that the adult is presenting, whereas when they in nonengaged shared attention, the child is not. able to see what his options are. For example, while a mother and child are both looking at the fire truck, the mother demonstrates how to play with the truck by moving the ladder and placing the fireman on the truck. This thereby allows the child to choose which one of these options, if any, he will decide upon. If a mother and child are not engaged with one another, represented by a lack of interactions between them, the child will not have any options to choose from because the mother is not demonstrating any.

Obligation choice co-construction behaviors can only occur in the context of engaged shared attention, and are devised to help the child come to see that certain expectations are followed by obligations (Stilson, 1993). The ways in which mothers and children can obligate themselves is by through demonstrations, affirmations, and corrections.

Stilson (1993) investigated the extent to which a social context limits or promotes a child's behavior and the subsequent style that will result. While Stilson (1993) investigated sharing attention, rituals, and obligation choice co-constructions under Harding et al.'s (in press, 1996, 1995, 1987, 1985, 1984, 1982) Choice Construction Model, only her experimental design and results pertaining to obligation choice co-constructions will be explored. Stilson (1993) modified Harding's (1995) obligations choice constructions and proposed a model in which affirmations and demonstrations were labeled "options-promoting" and commands, corrections, and 
object replacements were labeled "options-limiting." In a longitudinal study, Stilson examined the behaviors and mother-child relationship of children when they were 18 and then 40-months old. Stilson (1993) hypothesized that options-promoting behaviors would be related to more time spent in symbolic play, while options-limiting behaviors would be related to more time spent in nonsymbolic play. When children were 18-months old, mothers and children played with a variety of toys that allowed them to engage in levels of play ranging from unitary to representational play. This contrasted to the 40 -month visit, in which children were asked to play with their mothers according to a particular play sequence that was limited in toy selection.

Her results showed that options-promoting behaviors were significantly related to the amount of time that the mother-child dyad spent engaging in symbolic play for the 18-month olds, and interactive options-promoting behaviors at 18 -months was significantly correlated to interactive options-promoting behaviors at 40 -months. Options-limiting behaviors were not found to be significantly related to symbolic play at 18-months and at 40-months of age. The concurrent relationship between optionspromoting interactive behaviors and symbolic play, support the ideas that these mother-child behaviors tap the cognitive abilities of a child. These cognitive abilities are thought to develop into divergent and convergent thinking styles. Stilson (1993) proposes that the predictive relationship between symbolic play and options-promoting interactive behaviors suggest that the child's symbolic play may temporally precede the interactive style adopted by the mother-child dyad.

Stilson (1993) found that interactive options-promoting behaviors at 18-months 
was significantly correlated to symbolic play at 40 -months, thereby lending support to the idea that children's options-promoting social interactions are related to concurrent and subsequent symbolic play. Options-limiting social interactions at 40 -months was found to be significantly correlated to high incidences of nonsymbolic play at 40 months. Stilson (1993) suggests that options-limiting social contexts may interfere with the 40 -month olds ability to engage in symbolic play, even though the cognitive abilities for symbolic play may be present at 18 -months.

Although these exploratory findings are provocative, the questions remains as to the extent that the mother-child interactive relationship promotes or limits choices and the level of subsequent symbolic and nonsymbolic play that the child engages in.

\section{Summary of Research Intent}

Based on Stilson's (1993) findings, this thesis project is designed to investigate the role that a mother's behaviors as either options-promoting or options-limiting will have on the child's frequency and levels of symbolic and nonsymbolic play.

Significant results will lend support to the model proposed by Stilson and Harding (in press) and Stilson (1993), and will validate findings that the interactive optionspromoting context initiated by mothers correlates with cognitive development, as measured by symbolic play, in children. The formulating of this research design integrates both the research and theory in the areas of the relationship between symbolic play/creativity and divergent/convergent thinking styles, the relationship between symbolic play and emerging cognitive abilities, and the influence that the interactive relationship between a mother and a child has on the child's cognitive 
development. From this literature, one research hypothesis has been generated.

It is hypothesized that an interactive options-promoting context will be related to children engaging in higher incidences of symbolic play, whereas an optionslimiting context will be related to a higher incidence of nonsymbolic play.

This hypothesis specifically targets Stilson and Harding (in press) and Stilson's (1993) findings in relation to symbolic play and obligating choice constructions (Harding et al., in press, 1996, 1995, 1987, 1985, 1984, 1982). Stilson (1993) suggests that the child's cognitive structures are already involved in a developmental process and are affected by the social influences from the mother, as the agent in the social interchange. Within this theory, this question specifically addresses whether or not an options-promoting dyadic behavior will be associated with more symbolic play. This may be linked to the development of a cognitive style, or divergent thinking, assuming that creativity is inherent in a child's ability to engage in symbolic representation. 


\section{CHAPTER 3}

\section{METHOD}

\section{$\underline{\text { Subjects }}$}

Mothers and children were recruited from the Loyola University Chicago Center for Children, Families, and Community "Baby 'N Me" program. Baby $\mathrm{N} \mathrm{Me}$ is a group for first-time mothers and their infants. Participants are recruited from the Chicago and northern suburbs through advertisements in local newspapers, parenting magazines, local hospitals, and flyer distribution. Most infants, at the time of enrollment in Baby ' $\mathrm{N}$ Me, range in age from 3-weeks to 10-months. All mothers reside, on average, within a 50-mile radius of Loyola's Mallinckrodt campus in Wilmette, Illinois. The mother-child dyads are self-identified as upper-middle class, maintain intact homes, and are primarily Caucasian.

Following the 5-week program, mothers are invited to participate in the longitudinal research project affiliated with the Center for Children, Families, and Community. Research topics include interaffectivity, attachment, cognitive development, intentional communication, and choice co-construction. All research participants sign a consent form indicating their interest in participating in the longitudinal research study (Appendix A). Mothers may withdraw their participation at any time. Mothers and children participate in studies during specific times during 
the developmental process, ranging from 10 -months to 18 -months.

All mothers from the Baby ' $\mathrm{N}$ Me program whose children ranged between the ages of 12 -to 48 -months were recruited by phone for this study. A total of 31 mothers and children participated. An additional mother and child, who did not participate in the Baby'N Me program, but joined the longitudinal research project, was included in the sample.

From the original sample pool of $\mathbf{3 2}$ mother-child dyads, two pairs were dropped from the study prior to analyses. The first mother-child dyad was dropped due to the child's attempts to interact more with the researcher than with the mother while the researcher was operating the video camera. The second mother-child dyad was not included in analyses due to the mother not following the experimenter's directions by feeding the child during the timed interactions. The final sample had a total of 30 mother-child dyads.

The average age of the 30 children in the sample was 29.9 -months old, ranging in age from 12-months to 47 -months (see Table 1). The final sample was composed of 17 boys and 13 girls. On average, mothers were married four years (range $=1-14$ years) and were 33-years old (range $=27-43$ years) at the time their first child was born, and had completed 17 years of education (range $=12-21$ years). No mothers experienced major complications during labor, and the children were full-term without major complications at birth. 
Table 1. Distribution of children's ages

\begin{tabular}{lc} 
AGE & \# SUBJECTS \\
\hline 12 & 1 \\
13 & 1 \\
14 & 1 \\
17 & 2 \\
19 & 2 \\
22 & 1 \\
23 & 3 \\
26 & 1 \\
27 & 1 \\
28 & 1 \\
30 & 1 \\
32 & 1 \\
34 & 2 \\
36 & 2 \\
37 & 2 \\
39 & 1 \\
40 & 1 \\
41 & 1 \\
42 & 2 \\
43 & 1 \\
45 & 1 \\
47 & 1 \\
\hline $\mathrm{M}=29.9$-months & $\mathrm{N}=30$
\end{tabular}




\section{Procedure}

Prior to the videotapings, toys not utilized in the structured and free play paradigms were positioned in the middle of the room to help acclimate the child. Videotaping did not begin until all instructions had been given and were understood by the child's mother, and the child was comfortable with the laboratory setting. Mothers and children were videotaped for five minutes of structured play and ten minutes of free play in the Center for Children, Families, and Community Baby ' $\mathrm{N}$ Me room at the University campus.

Videotaping of mother-child dyads: This study followed the videotape format utilized by Weissmann (1987), who adapted the Parent-Infant Early Relational Assessment by Clark, Musick, Stott, and Klehr (1985), to observe the interactive qualities between a mother and a child (Weissmann, 1987). Mother-child dyads were videotaped according to when the mother reported that the child would be most alert. For children 12-24-months, a booster chair with an adjoining table and a chair for the mother were set up in the middle of the room. Children over 24-months old and their mother sat at a table and chairs set up in the middle of the room. The videocamera was positioned towards the back of the room, allowing the mother and child to have sufficient playing space.

The interactive tasks that the mother and child completed during the five minute structured play paradigm was determined by the child's age (see Weissmann, 1987). This piece of data collection was part of the longitudinal Baby ' $\mathrm{N}$ Me parent education program. For this particular study, only the free play paradigm was of 
Figure 1. Choice co-construction interactive behaviors coded for 1502 -second intervals for each mother-child dyad.

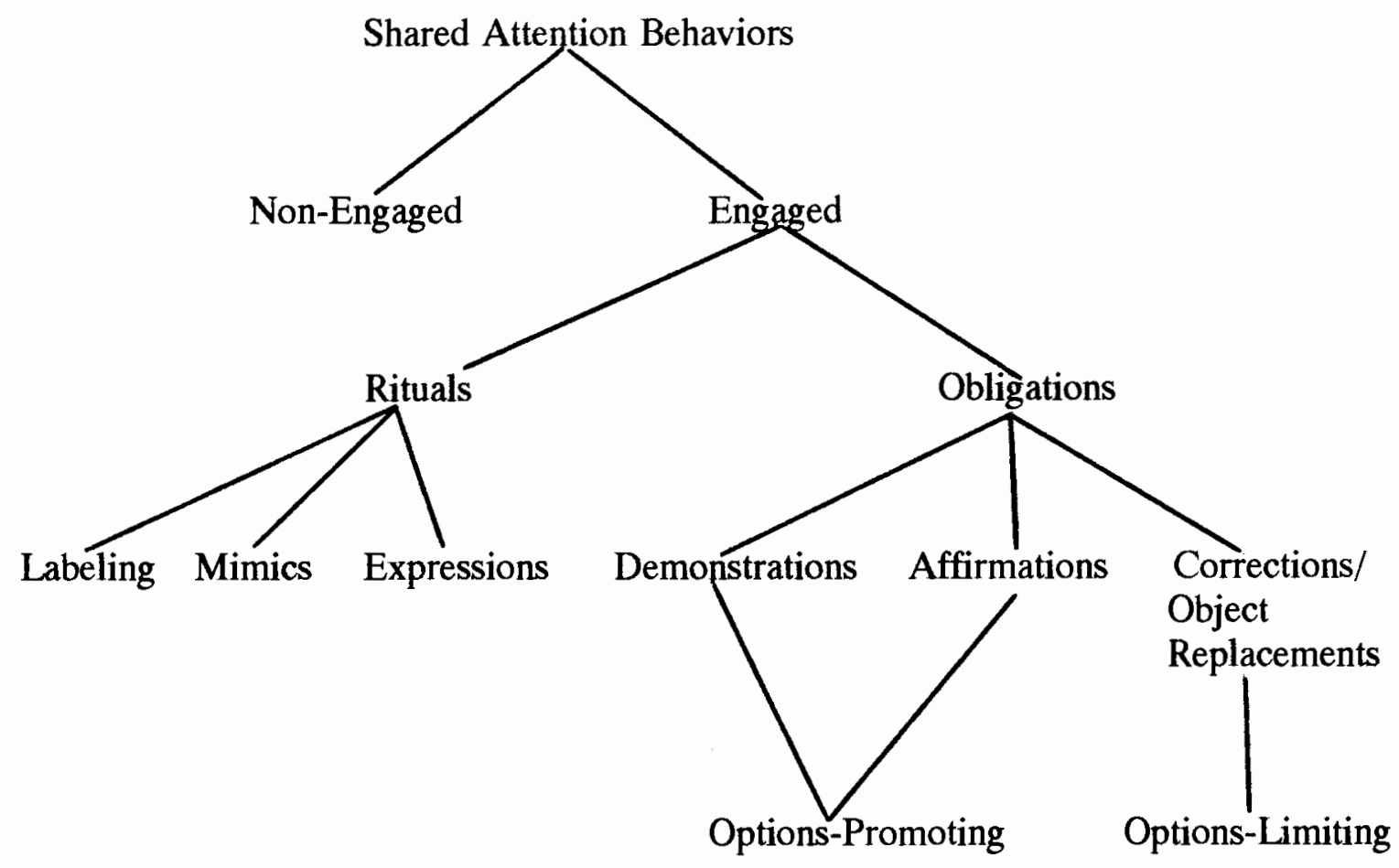


can only be coded if it occurs during "engaged shared attention." The 1502 -second intervals for each mother-child dyad was thus viewed three times and coded for shared attention behaviors, ritual behaviors, and obligations (Appendix B).

Shared attention behaviors: During the first viewing of each mother-child dyad interacting on tape, the shared attention behaviors between the mother and child were identified. Shared attention behaviors indicate the object or objects on which the mother and child are focusing on simultaneously. A mother and child were said to be non-engaged in shared attention when they were focusing or gazing upon the same object for at least one 2-second interval. For example, a mother and child could be focusing on the cars, while the child is moving them around the room. In this example, both are looking at the same object, but are not interacting with one another. Engaged shared attention behaviors are operationally defined as occurring when both mother and child gaze at one another or switch their gaze between an object and one another. For example, a mother and child would be said to be engaged when both mother and child were having their puppets interact with one another. Thus, when the shared attention is accompanied by vocalizations, smiling, or touching the mother and child are credited with being engaged with one another. Only when the mother and child are engaged can ritual or obligation be coded.

Rituals or stipulated behaviors: The same 1502 -second intervals were viewed a second time to identify the rituals or stipulated behaviors. Although these data were not used in the analysis of this thesis. Harding et al.'s (in press, 1996, 1995, 1987, $1985,1982)$ ritual behaviors are patterned after what Piaget (1962) defined as 
behaviors which establish a consistent pattern from which partners can respond. Rituals were coded according to the following subcategories: naming/labeling, mimicking, and expressions.

Obligations: The 1502 -second intervals were viewed a third time to code for obligation choice co-constructions (Appendix C). Harding et al.'s (in press, 1996, $1995,1987,1985,1982)$ scheme for obligations follows what Piaget (1962) cites as being directives by an adult, which signify the appropriateness of a behavior. Obligations were coded as either options-promoting or options-limiting (Stilson, 1993; Stilson \& Harding 1996). Options-promoting behaviors were coded when the adult demonstrated the way an activity should be carried out, or affirmed a child's behavior, either verbally or nonverbally. Options-limiting behaviors were coded when the mother showed disapproval with the way the child was interacting in a play activity, or placed the play object into a different position through object replacement.

From the 150 2-second intervals of choice co-construction coded measures, options-promoting and options-limiting frequencies were analyzed as predictor variables in the regression equation for nonsymbolic and symbolic play.

Interrater reliabilities for choice co-constructions were obtained by having two independent raters each code five of the mother-child dyadic interactions, for a total of $31 \%$ of the total sample. Interrater reliabilities were calculated prior to discussions between all raters. Agreements were reached by all raters on coding discrepancies prior to analyses. Interrater reliability was calculated by dividing the number of agreements by the number of agreements plus disagreements (Stilson, 1993; Stilson \& 
Harding, 1996). Reliabilities on the obligation choice co-constructions are as follows: $93 \%($ range $=82-100 \%)$ for demonstrations, $96 \%($ range $=88-100 \%)$ for affirmations, and $93 \%$ (range $=86-100 \%$ ) for corrections.

Coding scheme for nonsymbolic and symbolic play: Nonsymbolic and symbolic play was coded according to the scheme developed by Tamis Le-Monda and Bornstein (1994, 1991). Their Toddler Play Levels define a child's behavior across a continuum of eight levels of increasing symbolic representation (Appendix D). Each child's play was coded for 75 4-second intervals (Stilson, 1993; Stilson \& Harding, 1996). During each 4-second interval, the child's level of play was coded, across the eight Toddler Play Levels, and the total frequency for each level was summed (Appendix E). Levels one through four were summed together and classified as nonsymbolic play, while levels five through eight were summed together and classified as symbolic play (see Table 2).

Interrater reliability for the child's classification of play as nonsymbolic and symbolic play was determined by having one independent rater code five minutes from of the same 10 mother-child dyad tapes (or $31 \%$ of the sample) that was coded for the opposite five minute interval by independent raters for choice co-construction. Interrater reliability was determined prior to discussions on disagreements. All discrepancies in coding were discussed and agreements reached prior to analyses. For the purposes of this study, the total score for nonsymbolic play (i.e., levels 1-4) and the total score for symbolic play (i.e., levels 5-8) will be analyzed. Interrater reliabilities were determined by dividing the number of agreements and disagreements 
Table 2. Toddler play levels

Classification Play Level Definition

Nonsymbolic Play

1. Unitary Functional Activity Production of an effect that is unique to a single object.

2. Inappropriate Combinatorial Inappropriate juxtaposition of two or more objects.

3. Appropriate Combinatorial Appropriate juxtaposition of two or more objects.

4. Transitional Play

Approximation of pretense but without confirmatory evidence.

Symbolic Play

5. Self-directed Pretense

Clear pretense activity.

6. Other-directed Pretense

Clear pretense activity directed toward other.

7. Sequential Pretense

Linking two or more pretense actions.

8. Substitution Pretense

Pretense activity involving one or more object substitutions.

Note: Toddler Play Levels developed by Tamis-LeMonda and Bornstein $(1994,1991)$, coded for 75 4-second intervals. Analyses conducted on the subcategories of nonsymbolic play, the sum of levels one through four, and symbolic play, the sum of levels five through eight. Nonsymbolic and symbolic play served as dependent variables. 
for both the total score for nonsymbolic and symbolic play. The following are the reliabilities for child's play levels: $93 \%$ (range $=80-100 \%$ ) for nonsymbolic play and $93 \%$ (range $=70-100 \%$ ) for symbolic play 


\section{CHAPTER 4}

\section{RESULTS}

At the start of analyses, the relationship between demographical information and other data was investigated. Maternal characteristics (age of the mother at the time of the child's birth) the child's characteristics (gender and complications at birth) were not significantly associated with measures of optionspromoting, options-limiting, and total frequencies of nonsymbolic and symbolic play.

It is of interest to note that there was one significant finding between maternal and child demographics and the variables of interest. While these maternal and child characteristics were not under investigation for the purposes of this study, the finding is noted for future research purposes. Options-limiting was found to be inversely correlated with mother's education $(\underline{r}=-.345, \underline{p}=.036)$ and with length of marriage $(\underline{r}=-.321, \underline{p}=.048)$.

\section{Hypothesis}

It was hypothesized that the mother-child interactions that promote options through affirmations and demonstrations would be related to the child engaging in more frequent symbolic play; whereas the mothers' options-limiting behaviors of corrections and object replacements would be related to the child engaging in more frequent nonsymbolic play. 
Multiple regression analyses were used to examine the relationship and variability between the dependent variables (i.e., symbolic and nonsymbolic play) and the criterion variables (i.e., options-promoting and options-limiting obligation choice co-construction behaviors) (Appendix F). The frequency counts for both nonsymbolic play and symbolic play were calculated by summing the total frequencies of play in levels one through four to represent nonsymbolic play, and summing the total frequencies of play in levels five through eight to represent symbolic play (maximum of 75 -intervals based on four-second intervals for five minutes). The optionspromoting variable for each mother-child dyad was the sum of the possible 150 intervals of obligation choice co-construction demonstrations and affirmations that the mother engaged in (two-second intervals for five-minutes). The options-limiting variable for each mother-child dyad was the sum of the possible 150-intervals (twosecond intervals for five-minutes) of obligation choice co-construction corrections and object replacement behaviors that the mother engaged in.

Nonsymbolic play versus options-promoting and options-limiting: In Table 3, correlation coefficients are reported. Options-promoting and nonsymbolic play were inversely related $(\underline{r}=-.333, \underline{p}=.036)$, and options-limiting and nonsymbolic play were directly related $(\underline{r}=.321, \mathrm{p}=.042)$. Figure 2 further suggests that there is a relationship between nonsymbolic play and options-limiting and options-promoting. When the mean for nonsymbolic play was high, it appears that on average, mothers engaged in fewer options-promoting behaviors than when the child spent less time engaging in nonsymbolic play. However, options-limiting behaviors appears to follow 
Table 3. Correlation Coefficients for symbolic and nonsymbolic play with options-promoting and options-limiting

\section{Symbolic Play Nonsymbolic Play}

$\begin{array}{lll}\text { Options- } & r=.469 & r=-.333 \\ \text { Promoting } & p=.004^{*} & p=.036^{*}\end{array}$

$\begin{array}{lll}\text { Options- } & \mathrm{r}=-.589 & \mathrm{r}=.321 \\ \text { Limiting } & \mathrm{p}=.000^{*} & \mathrm{p}=.042^{*}\end{array}$

Note: ${ }^{*}=1$-tailed significance level 
Figure 2. Average frequency distribution of options-promoting and options-limiting by nonsymbolic play.

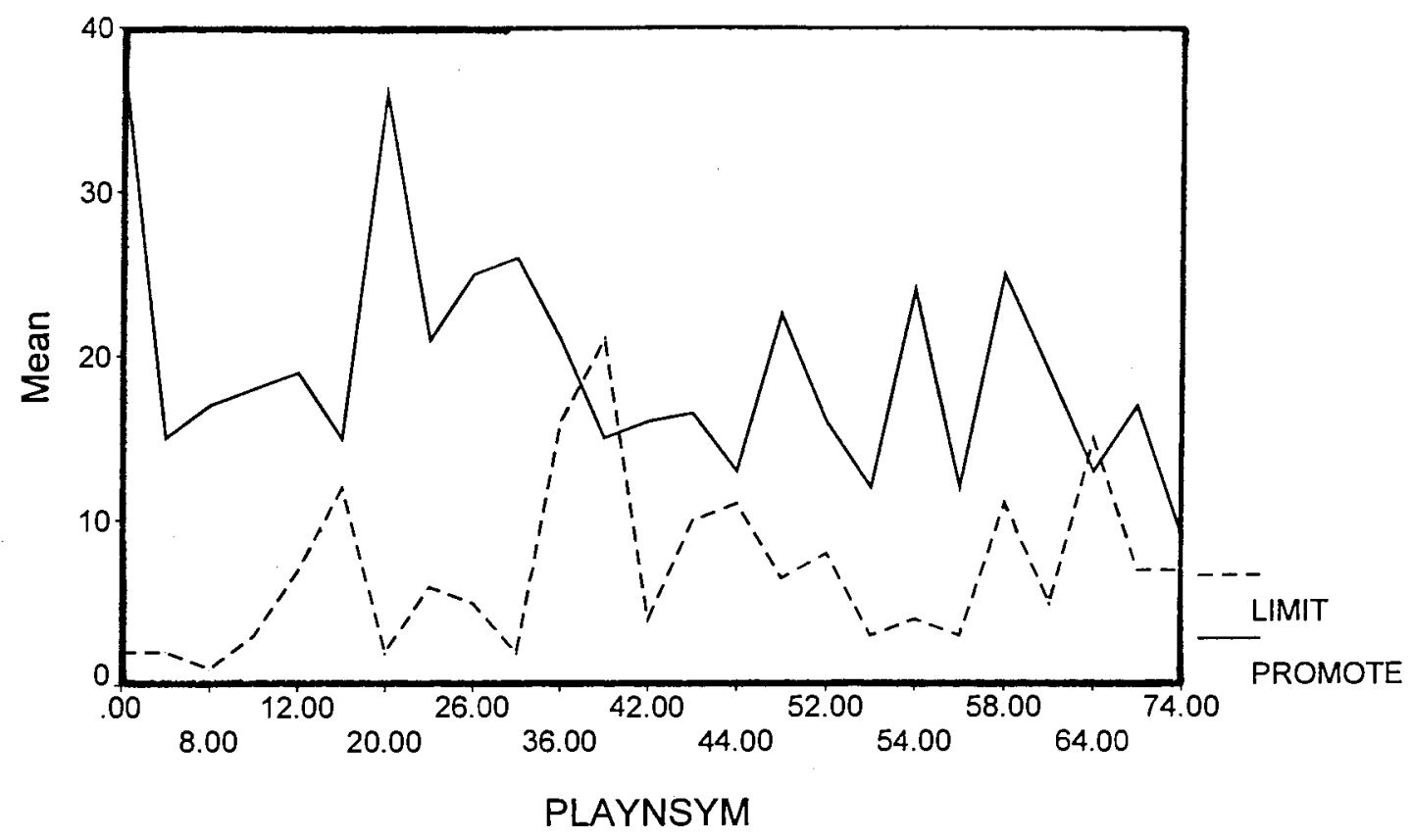


a more consistent pattern. This may suggest that options-promoting may play a greater role in influencing the subsequent level and frequency of symbolic play. Examining the relationship between options-promoting and options-limiting within nonsymbolic play, the multiple regression equation was not statistically significant $\left[\underline{\mathrm{R}}^{2}=.164, \underline{\mathrm{F}}(2,27)=2.644, \mathrm{p}=.089\right]($ see Table 4$)$. This result indicates that in and of themselves, options-limiting and options-promoting are each significant predictors of nonsymbolic play and thus account for a significant amount of unique variability in nonsymbolic play. However, when both variables are entered into the regression equation, the total variability is not statistically significant probably due to the small sample size. Independently, each variable accounts for approximately $11 \%$ of the variability, but together they only account for approximately $16 \%$ of the variability in nonsymbolic play. The loss of one degree of freedom in the regression equation serves to make the equation not statistically significant. This is a statistical anomaly due to the fact that options-limiting and options-promoting are moderately intercorrelated $(\underline{\mathrm{r}}=-.307, \underline{\mathrm{p}}=.049)$.

From these findings it appears that the amount of time that children engaged in nonsymbolic play behaviors was not significantly influenced by the type of behaviors that the mother engaged in, as either options-promoting or options-limiting. These findings do not support the hypothesis that children whose mothers engage in options-limiting behaviors will have a higher total frequency of nonsymbolic play. The inverse relationship between options-promoting and nonsymbolic play is what would be expected if the remainder of the hypothesis was supported for symbolic 
Table 4. Multiple regression equations for nonsymbolic and symbolic play with options-promoting and options-limiting as variables

$\mathrm{R}^{2} \quad \mathrm{~F}(2,27) \quad \mathrm{p}$

$\begin{array}{llll}\text { Nonsymbolic Play } & .164 & 2.64 & .089\end{array}$

Symbolic Play

.438

$10.5 \quad .000^{*}$

Note: ${ }^{*}=$ significance 
play, given that nonsymbolic behavior would have a lower total frequency when the mother engaged in an options-promoting interactive style. In essence, the trend suggests that children whose mothers' engage in options-promoting behaviors alone may engage in higher overall frequencies of nonsymbolic play, and options-limiting behaviors may independently be associated with higher levels of nonsymbolic play. Thus, nonsymbolic play cannot be predicted by the mother's overall interactive style. As shown in Table 5, the large standard deviation within nonsymbolic play $(\underline{\mathrm{M}}=36.50, \underline{\mathrm{SD}}=21.43)$, in comparison to the mothers' options-promoting behaviors $(\underline{\mathrm{M}}=19.00, \underline{\mathrm{SD}}=6.923)$ and options-limiting behaviors $(\underline{\mathrm{M}}=6.900$, $\underline{\mathrm{SD}}=5.095)$ suggests that what may be influencing the frequency of nonsymbolic play in children may be more related to a characteristic of the child than a function of the social context created by the mother.

Symbolic play related to options-promoting and options-limiting: The correlation coefficients in the multiple regression analyses indicate that there was a statistically significant amount of shared variability between symbolic play and options-promoting behaviors, and symbolic play and options-limiting behaviors (see Table 3). There was a direct relationship between symbolic play and optionspromoting behaviors $(\underline{\mathrm{r}}=.469, \mathrm{p}=.004)$ and an inverse relationship between symbolic play and options-limiting behaviors $(\underline{\mathrm{r}}=-.589, \underline{\mathrm{p}}=.000)$. As Figure 3 presents, as the average frequency of symbolic play increases, options-promoting behavior increases while options-limiting behavior decreases. These findings support the hypothesis that a child may engage in more symbolic play when interacting with a 
Table 5. Means and standard deviations of symbolic and nonsymbolic play, and options-promoting and options-limiting

\begin{tabular}{llll} 
& M & SD & Range \\
\hline Symbolic Play & 21.17 & 22.4 & $0-67$ \\
\hline Nonsymbolic Play & 36.5 & 21.4 & $0-74$ \\
\hline Options-Promoting & 19.0 & 6.92 & $9-38$ \\
\hline Options-Limiting & 6.90 & 5.10 & $1-21$ \\
\hline \hline
\end{tabular}


Figure 3. Average frequency distribution of options-promoting and options-limiting by symbolic play.

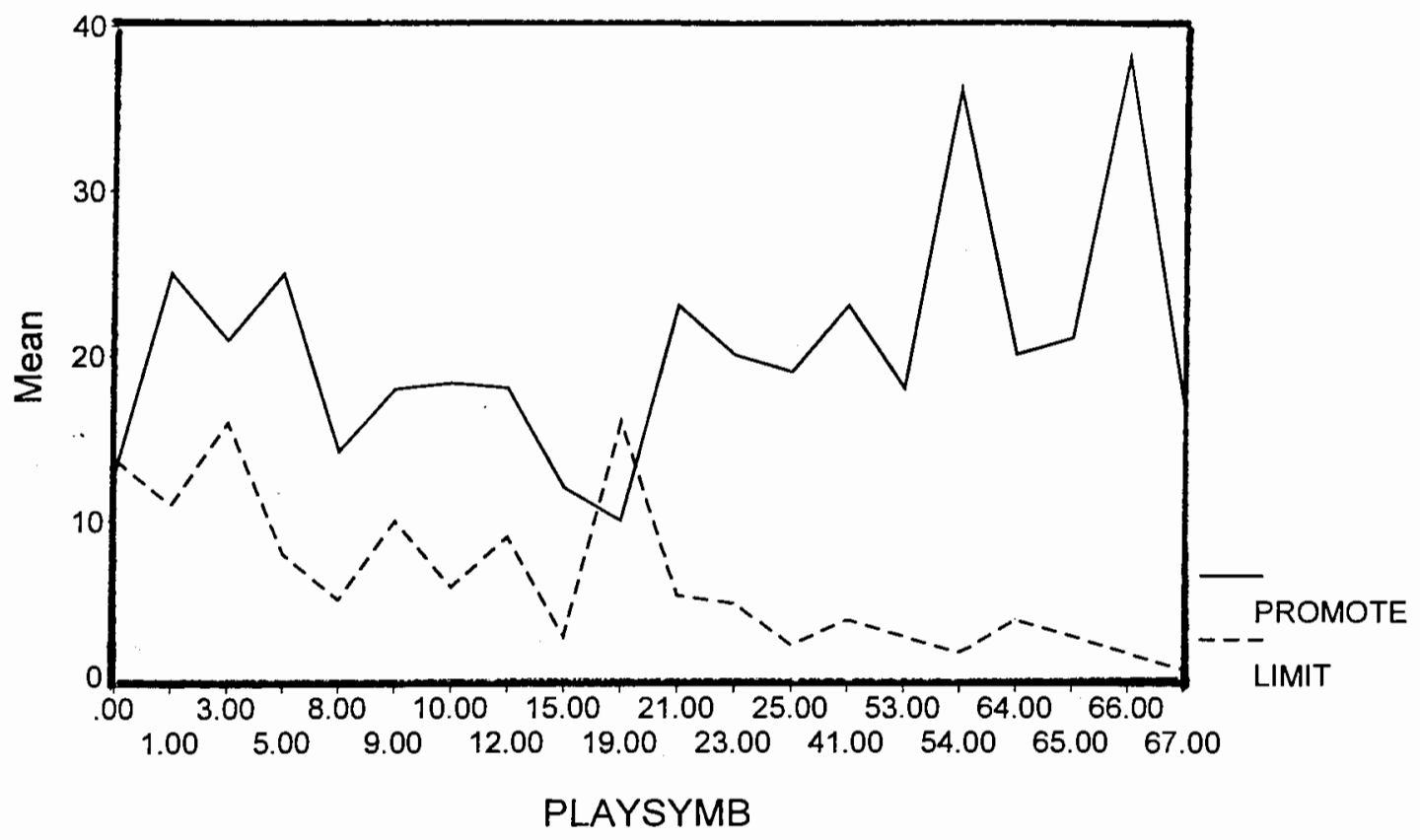


mother who engages in options-promoting behaviors and less time in symbolic play when the mother engages in options-limiting behaviors.

The multiple regression equation looking at the relationship between optionspromoting and options-limiting within symbolic play found that both options-limiting and options-promoting behaviors account for a significant amount of variability in symbolic play $\left[\underline{\mathrm{R}}^{2}=.438, \underline{\mathrm{F}}(2,27)=10.5, \underline{\mathrm{p}}=.000\right]$. This suggests that optionspromoting and options-limiting behaviors account for $44 \%$ of the variability in the symbolic play behaviors observed. In addition, both options-promoting $(\underline{B}=.318$, $\underline{\mathrm{t}}=2.012, \underline{\mathrm{p}}=.045)$ and options-limiting $(\underline{\mathrm{B}}=-.491, \underline{\mathrm{t}}=-3.241, \underline{\mathrm{p}}=.003)$ behaviors account for a significant amount of unique variability, and are thus good predictors of symbolic play (see Table 6). From these findings it appears that the extent to which the mother-child interactive relationship either promotes or limits choices influences the amount of symbolic play that a child engages in. The large standard deviation within symbolic play $(\underline{\mathrm{M}}=21.7, \underline{\mathrm{SD}}=22.4)$ may be due to possible variation in cognitive abilities within the sample (see Table 5). 
Table 6. Options-promoting and options-limiting as variables in the significant multiple regression equation for symbolic play

B $\quad \mathrm{t} \quad \mathrm{p}$

Options-Promoting $\quad .318$

$2.01 \quad .045^{*}$

Options-Limiting

$-.491$

$-3.24$

$.003^{*}$

Note: ${ }^{*}=.05$ significance level 


\section{CHAPTER 5}

\section{DISCUSSION}

The purpose of this study was to examine the model presented by Stilson and Harding (in press) and Stilson (1993) in which symbolic play is proposed to be the intermediary link between the development of divergent/convergent thinking styles and the maternal characteristics in mother-child relationships. Thus, this study was designed to investigate to what extent the mother's behaviors, as either optionspromoting or options-limiting, influenced the amount of time that children engaged in symbolic and nonsymbolic play.

A mother was said to provide an options-promoting social context when she demonstrated activities for the child and affirmed the child's behaviors, while an options-limiting social context was identified when she corrected the child's behaviors and manipulated the child's playing objects. The significance of the mother's interactive behaviors as options-promoting and/or options-limiting is that it suggests the extent to which the mother promotes or limits the child's play options (Stilson \& Harding, in press). These mother-child interactive behaviors, which either promote or limit the child's behaviors, were predicted to relate to the child's ability to engage in symbolic representation, and to subsequently increase their play repertoire by encouraging more symbolic play options. It is suggested that the child's ability to employ more symbolic options in play and within the social contexts is related to the 
development of a particular cognitive style, for example, divergent or convergent thinking (Stilson, 1993); Stilson \& Harding, in press).

\section{Hypothesis Testing}

It was hypothesized that mother-child interactions that promote options through the use of the mother's affirmations and demonstrations would be related to symbolic play on the part of the child. Conversely, options-limiting behaviors of corrections and object replacements were hypothesized to be related to nonsymbolic play.

Findings support the hypothesis, given that the child's level and frequency of symbolic and nonsymbolic play were related to the mother-child options-promoting and options-limiting interactive behaviors. Regardless of the child's age, symbolic play and nonsymbolic play significantly correlated with the mother-child interactive context (i.e., options-promoting or options-limiting). Thus, children in an optionspromoting environment spent more time playing symbolically than children involved in an options-limiting context.

These findings support the model proposed by Stilson and Harding (in press) and Stilson (1993) in which symbolic play is related to mother-child interactive behaviors. According to this theoretical model, it is proposed that a child whose mother establishes a social environment that promotes options will develop a thinking style that examines possible options. The predictive relationship between symbolic play and options-promoting/options-limiting may serve to be a step in the child's cognitive processes that develops into a divergent thinking style.

For example, if a mother-child interactive relationship is characterized by 
demonstrations and affirmations which both present and affirm the process of creating and choosing options, the child may develop an options seeking style. As the child continues to be exposed to, and thus experienced at choosing options, these may serve as the foundation of an options-promoting or divergent cognitive style.

In contrast, nonsymbolic play was not found to be predicted by optionspromoting and options-limiting interactive behaviors, thus not supporting the second part of the hypothesis. According to this finding, the amount of time that children engaged in nonsymbolic play behaviors was not significantly influenced by the type of interactive behaviors that the mother engaged in.

Given these findings, further analyses were conducted to further examine the relationship between symbolic and nonsymbolic play, and options-promoting and options-limiting interactive styles. Exploratory questions focused on examining the significant multiple regression equations for symbolic play which revealed that approximately $44 \%$ of the unique variability could be accounted for by the relationship between options-promoting and options-limiting behaviors (see Table 4). Conversely, the nonsignificant multiple regression equation for nonsymbolic play found that approximately $16 \%$ of the variability could be accounted for. These findings suggest that there may be some specific qualities about options-promoting and options-limiting behaviors, in combination which other factors, that may influence the amount of time that a child spends in nonsymbolic and symbolic play activities.

Since symbolic representation is thought to emerge around the age of 13months and fully develop during the preschool years, the child's age at the time of the 
study was examined to see if it played a role in the total frequency of symbolic and nonsymbolic play (Piaget, 1962). As shown in Table 7, the child's age was found to be significantly correlated with symbolic play $(\underline{r}=.567, \underline{p}=.001)$ and with nonsymbolic play $(\underline{r}=-.404, \underline{p}=.013)$. The direct relationship between age and symbolic play was expected given the emergence of symbolic representation with developing cognitive ability. The inverse relationship between age and nonsymbolic play also follows the expected trend, suggesting that a child's time spent engaging in nonsymbolic activities will on the average, decrease as the child ages. These findings suggest that the amount of time that a child spends engaging in both symbolic and nonsymbolic play can be in part accounted for by the age of the child as a function of the child's cognitive development.

According to the significant multiple regression equations, age was found to account for a significant amount of unique variability in both symbolic $(\underline{B}=.567$, $\underline{\mathrm{t}}=3.647, \underline{\mathrm{p}}=.001)$ and nonsymbolic play $(\underline{\mathrm{B}}=-.404, \underline{\mathrm{t}}=-2.357, \underline{\mathrm{p}}=.026)$ (see Table 7). The importance of this finding was that age approximately accounted for $32 \%$ of the unique variability in symbolic play $\left(\underline{\mathrm{R}}^{2}=.322\right)$. Conversely, age approximately accounted for $16 \%$ of the unique variability in nonsymbolic play $\left(\underline{\mathrm{R}}^{2}=.163\right)$. This suggests that some other factor(s) influence the amount of time that children spend engaging in both symbolic and nonsymbolic play. In addition, the differences between the percentages supports the notion that interpreting symbolic play must include multiple factors. As the findings in this study suggest, not only may the social context (i.e., options-promoting) be influencing the 
Table 7. Correlation coefficients and multiple regression equations for symbolic and nonsymbolic play with child's age

\section{Symbolic Play Nonsymbolic Play}

$\begin{array}{clll}\text { Child's Age } & \mathrm{r} & .567 & .404 \\ & \mathrm{p} & .001^{*} & .013^{*} \\ \mathrm{R}^{2} & .322 & .163 \\ & \mathrm{~F}(1,28) & 13.2 & 5.46 \\ \text { Sig F } & .001 & .027 \\ \mathrm{~B} & .567 & -.404 \\ \mathrm{t} & 3.65 & -2.34 \\ \text { Sig t } & .001 & .027\end{array}$

Note: ${ }^{*}=1$-tailed significance level 
amount of time that a child spends in symbolic activities, but there may be other factors influencing the amount of time that a child spends engaging in nonsymbolic play.

An explanation for the lack of predictability between nonsymbolic play and options-promoting and options-limiting interactive styles (i.e., 16\% of the variability in nonsymbolic play versus $44 \%$ in symbolic play) may be due to the child's engagement with nonsymbolic activities, despite the options made available to the child and the child's own representational capabilities. Based on the novelty of the toys, some children appeared to "choose" to engage in more sensorimotor, less symbolic games, such as playing with a busy box. Despite the efforts by some of the mothers to engage the child in symbolic play, the child consistently would alternate between symbolic and nonsymbolic play. One implication of this finding may be that a child's play may continue to have an element of nonsymbolic play. In this sense, a child may begin to stack blocks (i.e., nonsymbolic play) and later form the goal of making a microphone out of the blocks (i.e., symbolic play). Some children's play may continue to include nonsymbolic play even when their interactive context and their cognitive abilities would correlate their ability to engage in symbolic play. This explanation reflects Nicolich's (1977) characterization of the evolution of play as "moving from object exploration and realistic object use to extended pretend sequence and then to planned sequences." It may be that when children come into contact with an unfamiliar object, their play must pass through this evolutionary process. This may in part be related to the child's motivation to symbolize. For the purposes of this 
study, a child's motivation to symbolize may not be related to the child's experiences in an options-promoting or options-limiting context. Children who engaged in a higher frequency of nonsymbolic play, despite sophistication of their cognitive abilities to symbolize, may have not been motivated to symbolize. In other words, the mother's social context (i.e., options-promoting or options-limiting) may not have been influential enough to motivate them to choose symbolic play options.

Another possible explanation for children's continuing engagement in nonsymbolic play despite their cognitive abilities is posited by McCune et al. (1994), who characterized the process of mutual regulation. They proposed mutual regulation to focus on two dynamics: the child's level of maturity as referenced by cognitive abilities; and the mother's calibration of her own role in relation to the child's level of cognition and her overall level of responsiveness (Clarke-Stewart, Vanderstoep, \& Killian, 1979; Rocissano \& Yachmink, 1983). Thus, if the mother overestimates or underestimates her child's abilities, their relationship is no longer balanced by the equal exchange between their behaviors with one another. With respect to this study, some of the mothers whose children were engaging in nonsymbolic play may have underestimated their childs' abilities and thus not provided symbolic play options. Without these symbolic play options, some of the children may have not been motivated to engage in symbolic play. Conversely, mothers may have overestimated their children's cognitive abilities to engage in symbolic representation by providing sophisticated symbolic options that were too complex for the child's cognitive structures to grasp. 
These two explanations in sum suggest that children may continue to engage in nonsymbolic play in part due to their motivation to symbolize, which may be influenced by their experiences within the social context created by their mothers. The findings in this study thus give further support to the findings of Dunn and Wooding (1977) and O'Connell and Bretherton (1984) who hypothesized that a child's motivation to symbolize may be related to the child's experiences within symbolic play. Given that children whose mothers created an options-promoting social context were found to spend more time in symbolic play activities, the qualities of the optionspromoting social context (i.e., demonstrations and affirmations) were examined as a way to explore the nature of their promoting social context. Thus, while both demonstrations and affirmations were believed to capture different qualities within the social context, it was unclear the extent to which the child's symbolic play behaviors are influenced by the demonstrations and affirmations that a mother contributes to the social context. A demonstration was coded when the adult demonstrated the way an activity should be carried out either verbally or nonverbally and when a new toy was introduced into play by placing it into the child's present play or by introducing a new toy or theme to be explored. An affirmation was coded when the adult affirmed the child's behavior through verbalizations or gestures.

Overall, the 30 mothers in the sample demonstrated behaviors $(\underline{\mathrm{M}}=11.8$, $\underline{\mathrm{SD}}=4.95)$ for children to follow more than they affirmed $(\underline{\mathrm{M}}=8.17, \underline{\mathrm{SD}}=4.80)$ a child's behavior (see Table 8). As shown in Table 9 the correlation coefficients indicate that there was a direct relationship between symbolic play and demonstrations 
Table 8. Means, standard deviations, and correlation coefficients of demonstrations and affirmations by symbolic play

\section{Symbolic Play}

\begin{tabular}{lll}
\hline Demonstrations & $\mathrm{M}=11.8$ & $\mathrm{r}=.182$ \\
& $\mathrm{SD}=4.95$ & $\mathrm{p}=.168^{*}$ \\
& Range $=4-25$ & \\
\hline & & \\
Affirmations & $\mathrm{M}=8.17$ & $\mathrm{r}=.429$ \\
& $\mathrm{SD}=4.80$ & $\mathrm{p}=.009^{*}$ \\
& $\mathrm{Range}=4-22$ & \\
\hline Note: ${ }^{*}=1$-tailed significance level &
\end{tabular}


Table 9. Multiple regression equation for demonstration and affirmations within symbolic play

Demonstrations Affirmations

Symbolic Play

$$
\begin{array}{lll}
\mathrm{R}^{2}=.200 & \mathrm{~B}=.126 & \mathrm{~B}=.411 \\
\mathrm{~F}(2,27)=3.37 & \mathrm{t}=.727 & \mathrm{t}=2.37 \\
\mathrm{p}=.050^{*} & \mathrm{p}=.474 & \mathrm{p}=.025^{*}
\end{array}
$$

Note: ${ }^{*}=.05$ significance level 
$(\underline{r}=.182, p=.168)$ and a statistically significant relationship between symbolic play and affirmations $(\underline{r}=.429, p=.009)$. These findings may indicate that these maternal behaviors serve different purposes in promoting options.

As Figure 4 presents, it appears from the results that the time children spent engaging in symbolic activities increased when the overall amount of demonstrations and affirmations that their mothers presented increased. It is interesting to note that at the higher frequencies of symbolic play that mothers' affirmations appear to not follow a pattern, while demonstrations maintained a relatively stable state. In the lower frequencies, mothers appear to give a similar number of affirmations and demonstrations. This may be related to individual differences or a factor of the child's age.

According to the multiple regression equation $\left[\underline{R}^{2}=.200, \underline{F}(2,27)=3.37\right.$, $\mathrm{p}=.050 \mathrm{~J}$, both demonstrations and affirmations were found to account for a significant amount of variability (see Table 9). However, only affirmations were found to account for unique variability in symbolic play $(\underline{B}=.411, \underline{t}=2.37$, $\mathrm{p}=.025)$ and were thus found to influence the overall total frequency of symbolic play. In addition, the strength of the beta weight for affirmations $(\underline{B}=.411)$ in comparison to that for demonstrations $(\underline{B}=.126)$ further suggests that the amount of time that a child spends playing symbolically is related to the amount of time that the mother affirms the child's behavior, rather than the number of demonstrations that the mother makes.

Thus, it appears that when the mother affirms a child's behavior, she appears 
Figure 4. Average frequency distribution of demonstrations and affirmations by symbolic play.

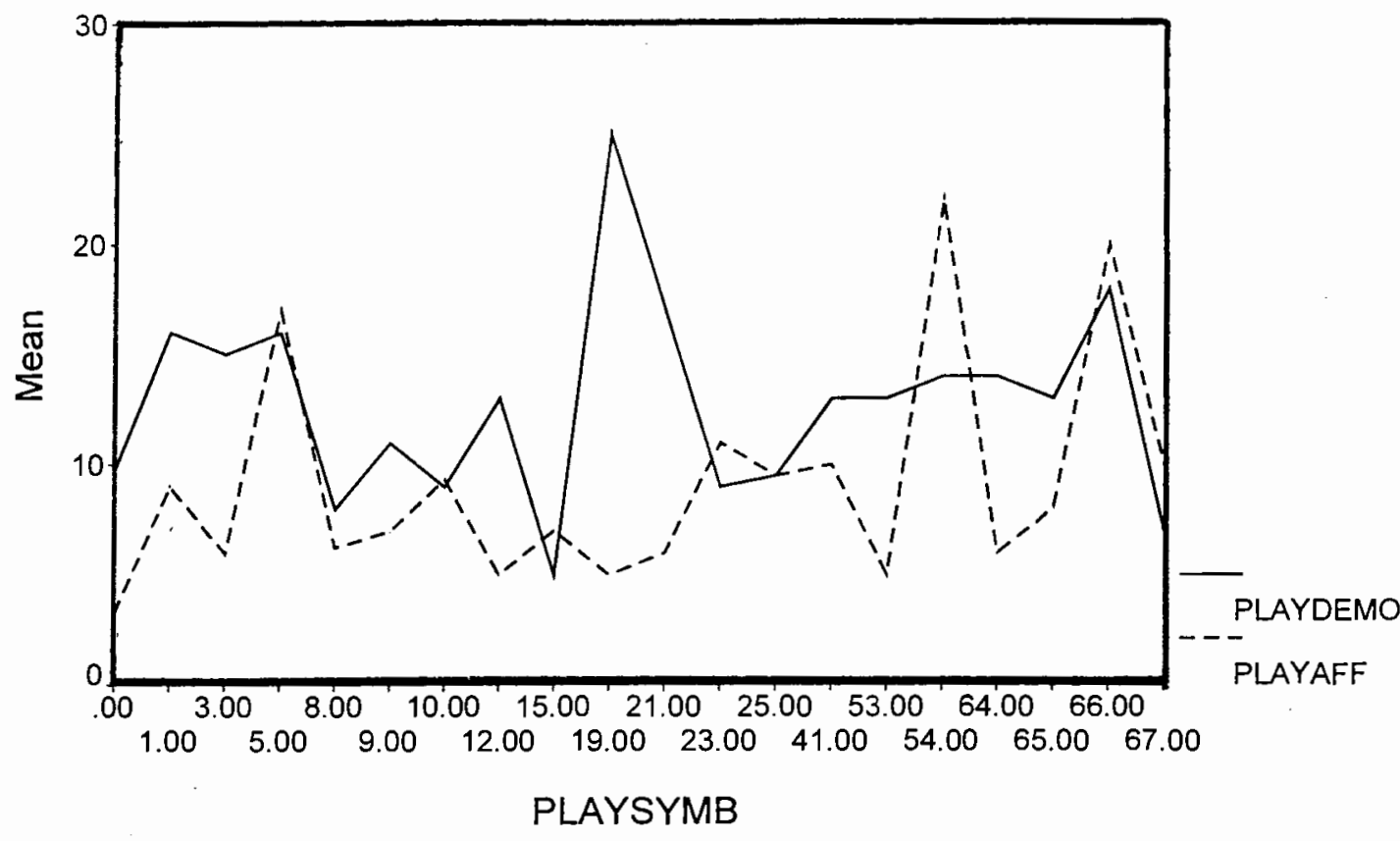


to not only be affirming the child's "choice," but also encouraging the child to repeat or extend the symbolic act. This differs from demonstrations, in that when a mother demonstrates "options" for the child, it is not clear that the child will replicate this behavior. Affirmations thus appear to contribute to the overall frequency of symbolic play, and may increase the likelihood that a child will again choose to look for options in play.

The exploratory questions examining the influence of the child's age and the influence of specific characteristics of the social context (demonstrating and affirming) give further support to the interactive nature that exists between the social context that the mother creates and the child's overall engagement in symbolic and nonsymbolic play. As a way to examine this interactive relationship more closely, the frequency distributions for symbolic play, nonsymbolic play, options-promoting, and optionslimiting were analyzed to determine if patterns existed with respect to age. To examine the relationship between age and these variables, the 30 children in the sample were divided into three groups: an older group for children ages 36-47months, a middle group for children ages 24-35-months, and a younger group for children ages 12-23-months.

As Figure 5 presents, the frequency distribution for symbolic play within each group suggests that within each age group there were children who differed in their cognitive abilities to engage in symbolic representation. An important note of discussion is the variability within some of the standard deviations (see Table 10). The variability within the oldest group may reflect the significant correlation between 
Figure 5. Frequency distribution of symbolic play by age groups.

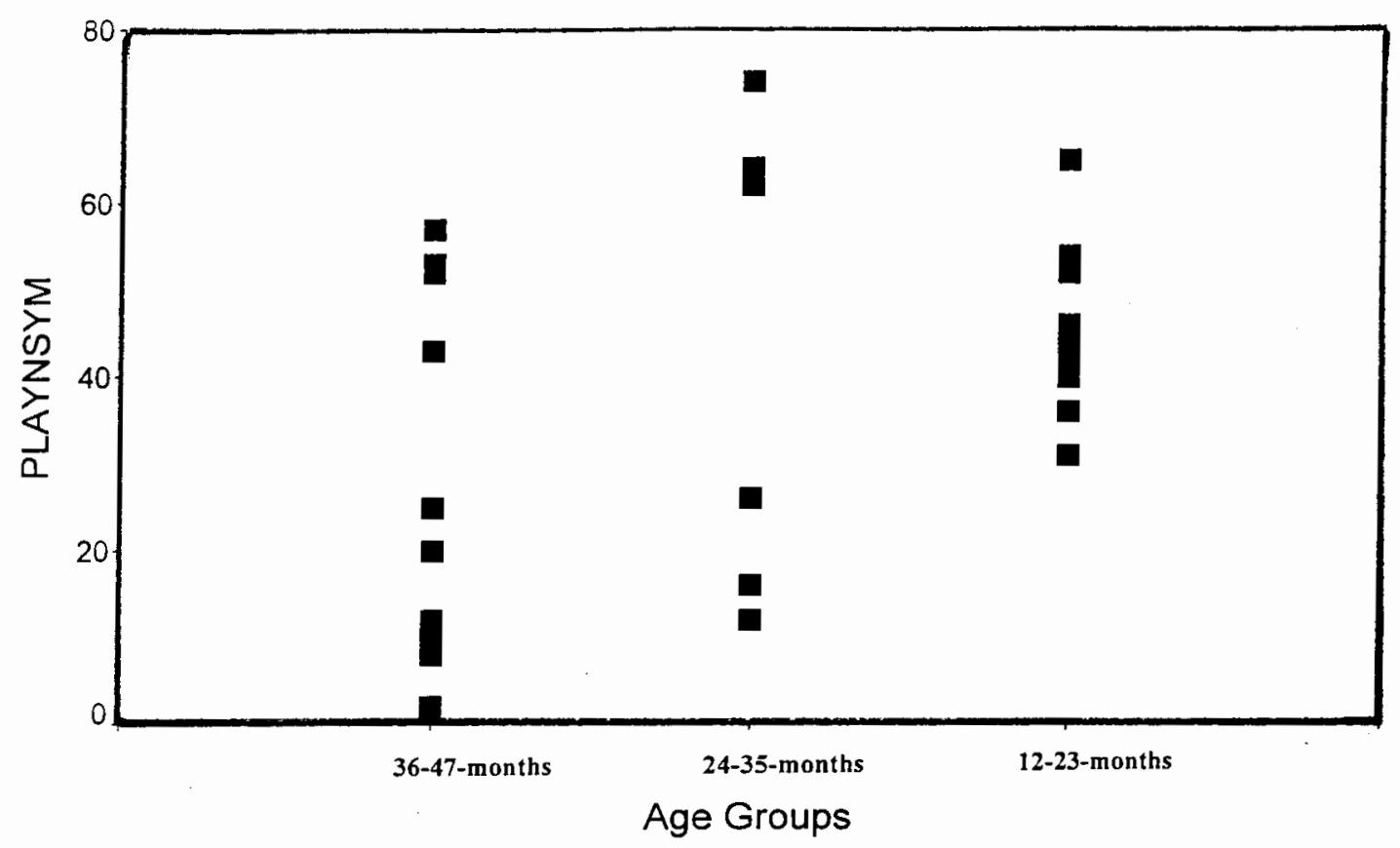


Table 10. Means and standard deviations of symbolic play, nonsymbolic play, options-promoting, and options-limiting by age groups

Age Groups

36-47-months

24-35-months

12-23-months

Symbolic

Play

$\mathrm{M}=38.9$

$\mathrm{M}=5.57$

$\mathrm{M}=13.2$

$\mathrm{SD}=24.4$

$\mathrm{SD}=7.85$

$\mathrm{SD}=12.0$

Nonsymbolic

Play

$$
\mathrm{M}=23.7
$$

$M=44.6$

$\mathrm{M}=45.4$

$\mathrm{SD}=21.8$

$\mathrm{SD}=25.7$

$\mathrm{SD}=9.20$

Options-

Promoting

Options-

Limiting
$\mathrm{M}=19.0$

$\mathrm{SD}=9.38$

$M=17.7$

$\mathrm{SD}=5.96$

$M=19.8$

$\mathrm{SD}=4.36$

$\mathrm{M}=9.30$

$\mathrm{M}=8.27$

$\mathrm{M}=4.25$

$\mathrm{SD}=3.77$

$\mathrm{SD}=5.80$ 
symbolic play and options-promoting and symbolic play and options-limiting. This may correspond to the frequency of time that the oldest group spent engaging in symbolic play. This variability may also be related to the development of cognitive abilities in children, which varies from child to child. In addition, the variability within the oldest age group may be related to the three subjects whose scores varied from the main frequency cluster. This divergence may be related to the development of early cognitive structures appropriate for symbolic representation, or may be a factor of the interactive relationship between symbolic play and options-promoting and symbolic play and options-limiting.

As shown in Figure 6, the variability within nonsymbolic play may be accounted for by either different cognitive abilities within each age group, the significant correlation between nonsymbolic play and options-promoting, which had an inverse relationship with nonsymbolic play. In addition, the variability within nonsymbolic play in the older and middle age groups may also be explained by the influence of the choice co-construction interactions of mothers and children independent of childrens' cognitive abilities.

While the means and standard deviations for symbolic and nonsymbolic play across the three age groups differed greatly, the means and standard deviations for options-promoting and options-limiting were relatively more stable. Further support for the stability within options-promoting is presented in Figure 7 and within optionslimiting is presented in Figure 8 . The relative stability within options-promoting and options-limiting behaviors across the three age groups suggests that the social context 
Figure 6. Frequency distribution of nonsymbolic play by age groups.

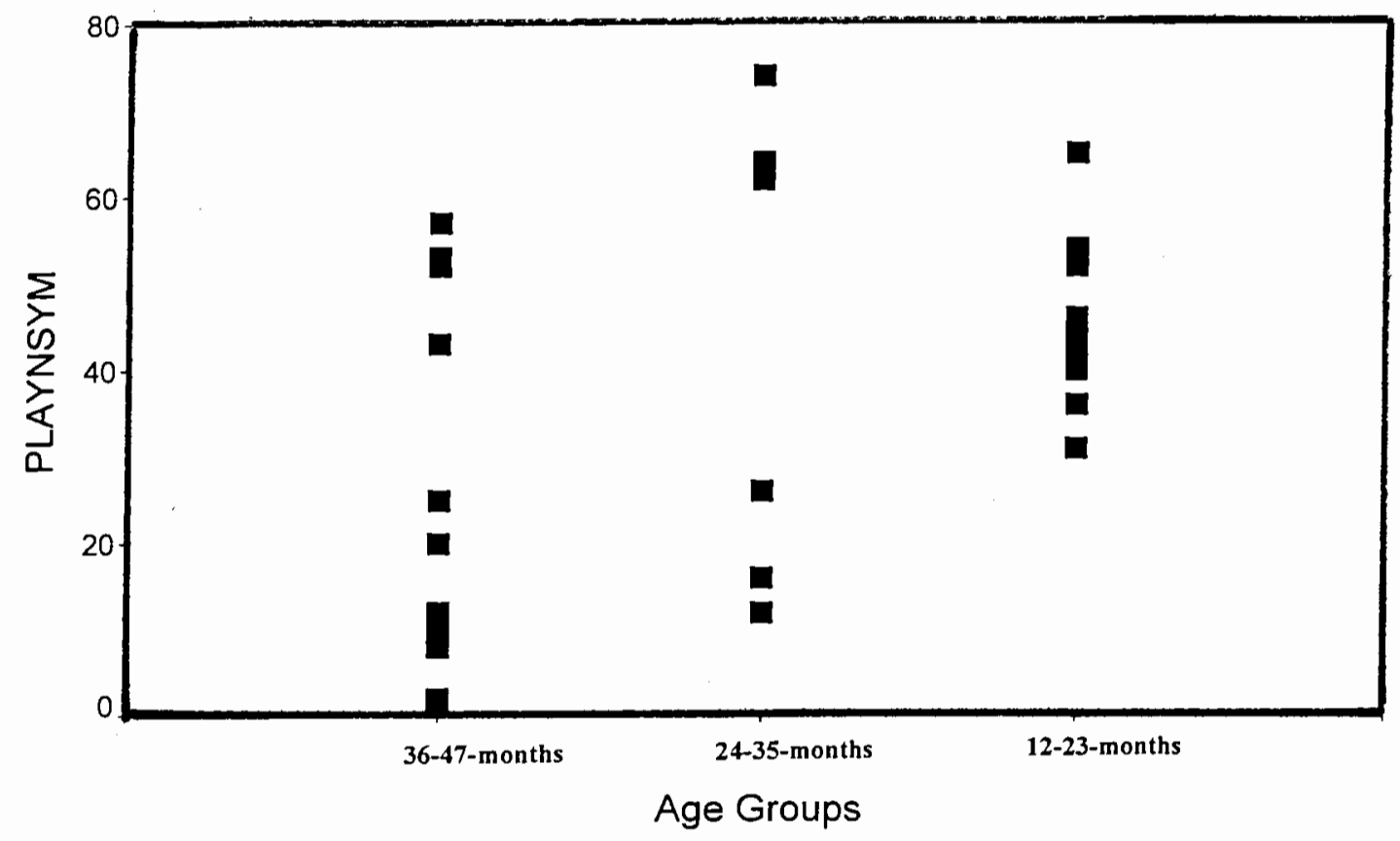


Figure 7. Frequency distribution of options-promoting by age groups.

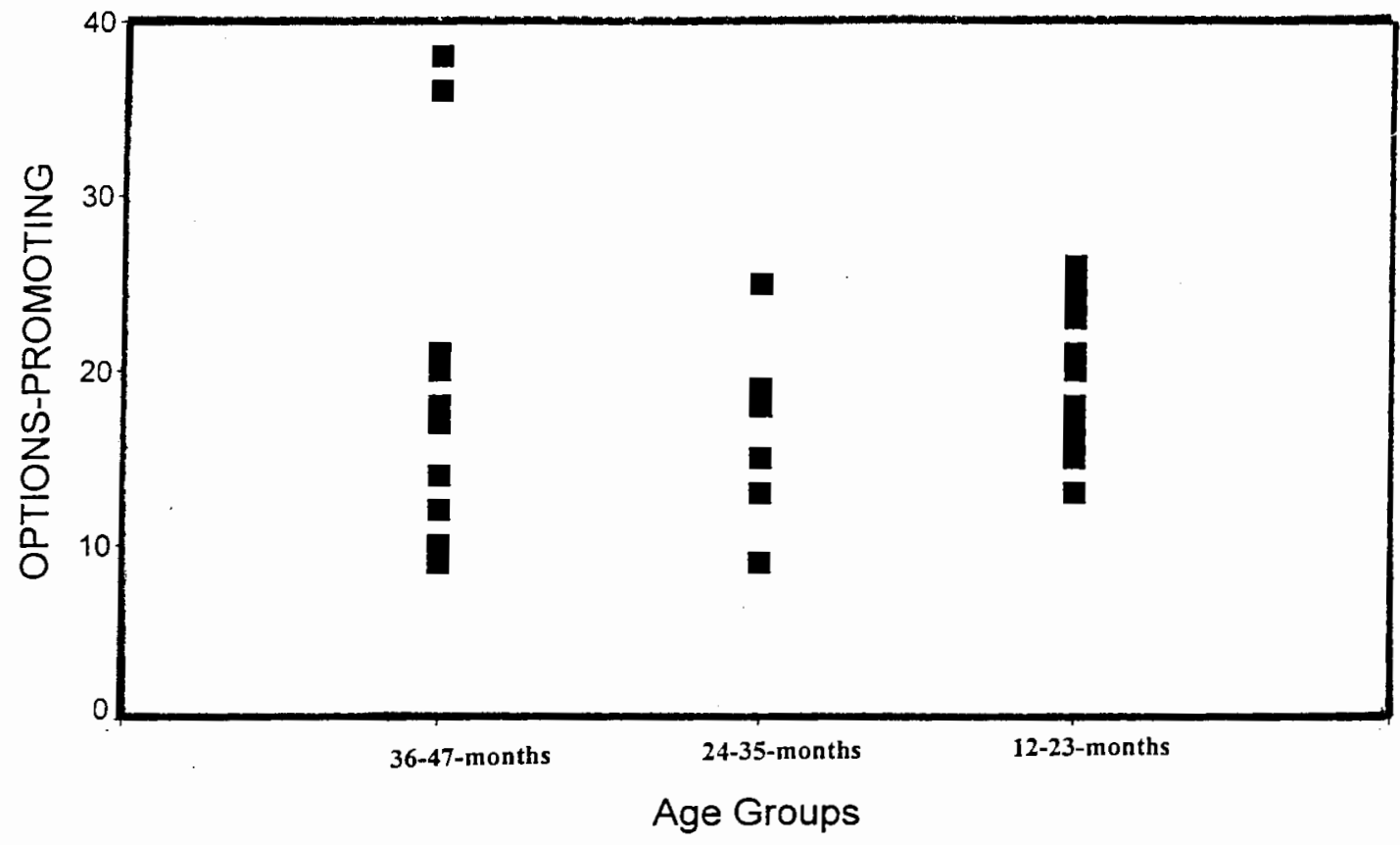


Figure 8. Frequency distribution of options-limiting by age groups.

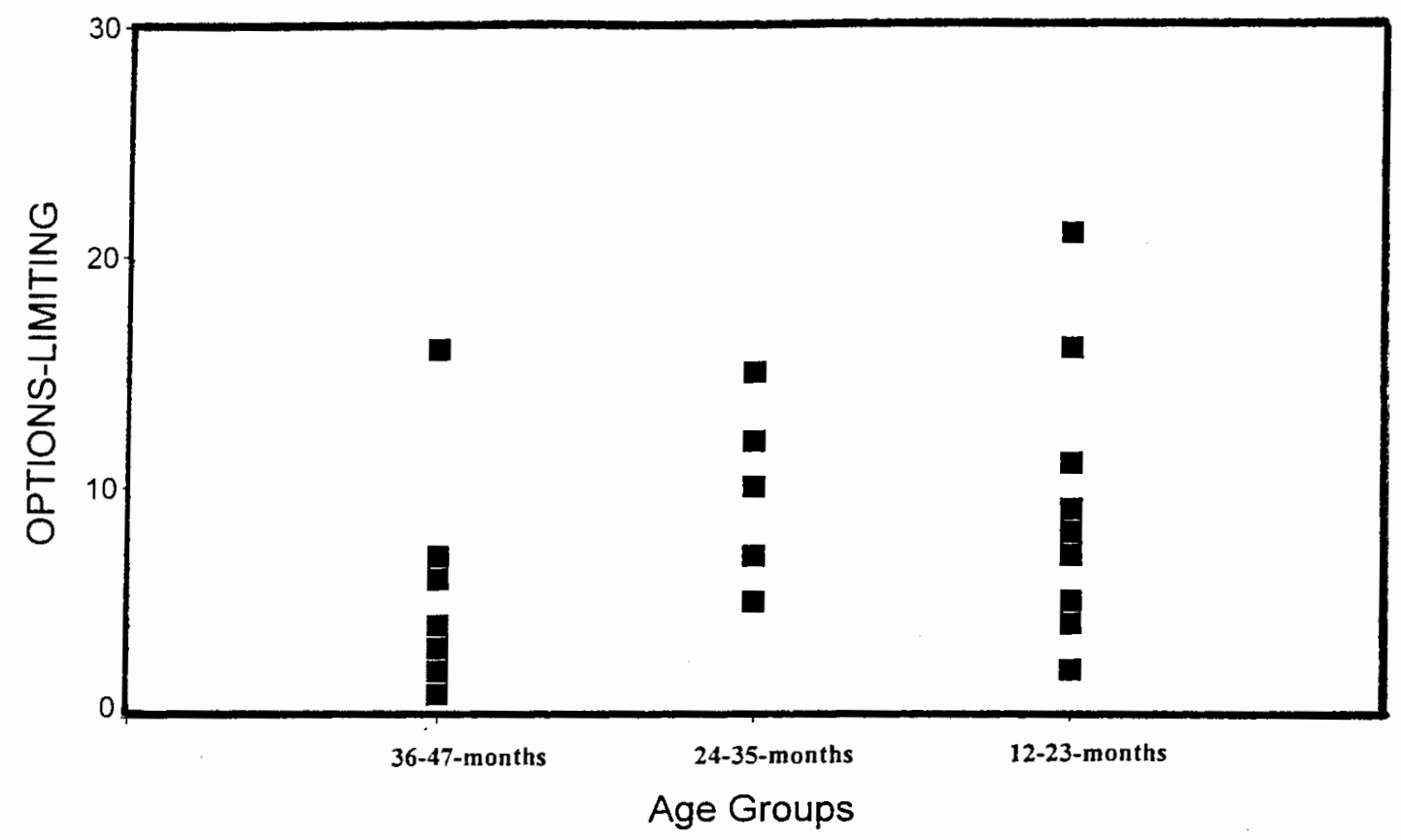


created by the mother, as either options-limiting and options-promoting, is an interaction style that remains stable as the child develops.

Thus, it appears that symbolic play dynamic developmental achievement, which may be influenced by the mother's options-promoting interaction style, while the consistency of the social context suggests that a mother may maintain her interactive style (i.e., options-promoting or options-limiting) throughout the child's stages of cognitive development.

\section{Conclusion}

While the results presented lend support to the findings in Stilson and Harding (in press) and Stilson (1993), and reflect the relationship between a child's symbolic and nonsymbolic play and the social context that the mother's interactive style as either options-promoting or options-limiting creates, there are several limitations in this study that should be noted.

All mother-child dyads were from middle- to upper-middle class, intact families, and most mothers had completed a college degree. Therefore, the findings should be cautiously generalized to other mother-child populations.

A few methodological issues merit comment. The room layout of the laboratory did not allow the experimenter and the videocamera to be hidden from the mother-child dyads. While most of the children did not appear to be influenced by the experimenter's presence, the overall effect that this had on the child's behavior is unknown. Mothers reported that their level of discomfort lessened as the taping progressed. The effects that the mothers' uneasiness had on the taping is thought to 
be negligible, since all dyads experienced the same laboratory/videotaping scenario, and these mothers were part of an ongoing parent education group that included frequent videotaping.

Future research should take into account the limitations of the present study. In addition, future research should increase the subject pool within each age group, to examine the development of thinking styles. In addition, future research should include attachment assessment in order to test Slade's (1987a, 1987b) findings that secure and insecurely attached children differed in their amount of symbolic play.

The cognitive developmental process is greatly influenced by the individual characteristics of the child within the mother-child relationships (McCune et al., 1994; O'Connell \& Bretherton, 1984). Thus, future research could examine temperament and parental stress data to determine if these variables correlated with mother and child variables under examination. It may be that characteristics measured by these instruments play a role in influencing the types of relationships that develop, which can have research and clinical implications.

In summary, significant findings suggest that both options-promoting and options-limiting behaviors are related to the amount of time that a child engages in symbolic and nonsymbolic play. Analyses of the research hypothesis found that children in an options-promoting social context created by the mother will spend more time engaging in symbolic play activities. Nonsymbolic play was interpreted as influenced by the child's motivation to symbolize as the child explores play objects. These options-promoting and options-limiting behaviors identify the mother's 
interactive style and are thought to remain relatively consistent throughout the child's development. Thus, a child's symbolic play marks a developmental achievement for the child, which is in part believed to be influenced by the social context created by the mother's interactive social style.

The theoretical model proposed by Stilson and Harding (in press) and Stilson (1993) in which symbolic play may serve an intermediary role between divergent or convergent thinking style and the mother-child interactive relationship, is in part supported by the predictive relationship between options-promoting and symbolic play behaviors. This connection between symbolic play, mother-child interactive behaviors, and divergent/convergent thinking styles may have implications in the area of child cognitive development for both researchers and clinicians.

In addition, while the cognitive ability of the child may be the main factor in predicting future cognitive abilities, McCune et al. (1994) suggests that when mothers are able to learn about the their own level of contribution within the mother-child relationship (i.e., options-promoting interactive style), they may modify their behaviors so as to influence the social exchange between mother and child. 
APPENDIX A

CONSENT FORM 


\section{LOYOLA UNIVERSITY CHICAGO}

CENTER FOR CHILDREN AND FAMILIES

CONSENT FORM

Project Title: Infant Development Within Infant-Parent Interaction

$\mathrm{I}$,

(Name of Signatory)

the parent or guardian of

(Name of Minor Subject)

a minor of (months) (years) of age, hereby consent to participate in, and consent to her/his participation in a research project being conducted by Lenore Weissmann, Ph.D., Susan Kromelow, Ph.D., Carol Harding, Ph.D., and Judith Arand, $\mathrm{Ph} . \mathrm{D}$., as well as other Loyola faculty and graduate students working with them under advice and supervision.

\section{Purpose}

The Purpose of this project is to trace the course of various aspects of normal infant development and infant-parent interaction throughout infancy. The areas to be explored include social, emotional, cognitive, and motor development. They will be looked at separately, and their inter-relationships examined, with regard to their potential contributions to learning more about the normal developmental course.

\section{Procedures}

1. As a result of my interest or involvement in Baby ' $\mathrm{N} \mathrm{Me}$, the Parent Support/Education program of the Center for Children and Families, I understand that I may be asked to participate in various aspects of the research project.

2. I understand that the group meetings of Baby ' $\mathrm{N}$ Me may be videotaped.

3. I understand that I may be asked to participate in several individual videotaped sessions with my infant over the course of time.

4. I understand that I may be asked to participate in several individual interviews, usually at the same time as the individual video sessions. These may relate to the taped episodes and other aspects of parenting. These discussions may be audiotaped. 
5. I understand that I may be asked to fill out questionnaires relating to infant development, parenting, and personality over the course of time.

Possible Discomforts

No discomforts are anticipated.

\section{$\underline{\text { Potential Benefits }}$}

Knowledge concerning factors which contribute to healthy infant development and parent-infant interaction may benefit those concerned with fostering optimal growth and development in children. Participation in the observation of my infant may contribute to my understanding of infant growth and development in general. However, I understand that it is possible that I may derive no individual benefit from participation, but that information gained from the study may benefit others.

\section{Alternatives}

None.

\section{$\underline{\text { Risks }}$}

No risk is involved.

\section{Confidentiality}

I understand that information which is obtained in connection with these procedures and which can be identified with me will remain confidential. I understand that information may be used for research, education and training purposes. My records will be identified by a number rather than by my name, and this number code will be available only to the researchers. Viewing of tapes for research, training and educational purposes will be done with complete anonymity.

I understand that any questions I may have regarding this research study will be answered.

I understand that no risk is involved, but that in any case I may withdraw myself and/or my child from participation at any time without prejudice, and that participation in "Baby "N Me" will not in any way be affected if we do not join the research project.

(Signature of Parent)

(Date) 
APPENDIX B

CHOICE CONSTRUCTIONS: DESCRIPTIONS AND CODING DEFINITIONS 


\section{CHOICE CONSTRUCTIONS: DESCRIPTIONS AND CODING DEFINITIONS}

1. Shared attention behaviors (engaged and non-engaged) are defined as most basic to a shared intentional communication structure. These behaviors are assumed to be the indicators of the intended or "chosen" direction and/or object of attention. How and on what communication partners choose to focus provides a basic defining characteristic for the functioning of their communication partnership. Smiling, mutual gaze, and touch (or their absence) appear to indicate that, in addition to focusing on the same event, object, or topic, communication partners are also engaged (or not engaged) with each other.

The operational definition for the "shared attention" category requires at least 2 -seconds of gazing by both partners at the same object (shared attention: nonengaged) or at each other (shared attention: engaged; can include gaze switching between object and each other). Vocalizing and/or talking, smiling, and touching may accompany the shared attention but are not necessary. Vocalizing is coded for the baby; talking for the mother.

2. Rituals or stipulated behaviors in acting out events are defined as behaviors that establish patterns of consistent action and response, in other words, expectations (see Piaget, 1965). The kinds of rituals that communication partners engage in and come to expect set the basic framework for that partnership and establish a working model against which other events and activities will be compared. Some of these rituals may be conventional, such as games of peekaboo and patty-cake and question games'. Other rituals may be idiosyncratic, appearing routinely in the shared context of an individual dyad's interaction.

Traditional rituals (structured games such as patty-cake or peekaboo) are coded (counted) as well as non-traditional jointly-shared structured behaviors. For sequence of behaviors to be identified as a non-traditional dyad-developed ritual, it has to include a sequence of behaviors employed by both partners and has to be observed

1Maternal questions appear to serve varied functions in the coding scheme and are coded according to the function they serve. For example, questions such as "Can you do it this way?" are coded as obligations, while a question such as "Do you see what mommy sees?" is coded as indicating shared attention. Question games including questions such as "How big is mommy's baby?" observed as part of ritualized sequence of behaviors engaged in by the mother and baby are coded as rituals. 
occurring at least twice during the two-minute interaction. Any vocalization or talking accompanying either type of rituals should be coded.

3. Obligations are defined as rules or implied directives as to the appropriateness or acceptability of behaviors (see Piaget, 1965). When one partner (usually the adult) within a communication partnership demonstrates or corrects or affirms, either through words or actions, the other partner comes to recognize that some choices are better than others, at least within that particular communication partnership.

Three types of obligations are coded. Vocalizing by the child and talking by the adult are coded within each category:

a. demonstrations: the adult demonstrates the way an activity should be carried out. The demonstration may or may not include vocalization which should be coded.

b. affirmations: the adult affirms the child's behavior through words ("Yes, that's the right way.") or through gestures such as clapping or nodding. Talking should be coded.

c. corrections: the adult corrects the child's behavior through words ("No, that's not how you do it.") or through gestures such as removing the toy or frowning. Object replacement is also coded as a correction. In this case, the adult manipulates the object into an appropriate position, for example, the adult places a toy in an appropriate position after the infant has turned it upsidedown. Talking by the adult must be coded when observed.

Note: Choice Construction Model derived from Harding et al. (in press, 1996, 1995, 1987, 1985, 1984, 1982). 
APPENDIX C

OBLIGATION CHOICE CO-CONSTRUCTION CODING EXAMPLES 


\section{OBLIGATION CHOICE CO-CONSTRUCTIONS CODING EXAMPLES}

Mother's Interactive Style Behaviors

\section{Options-Promoting}

\section{Definition and Examples}

Demonstrations

Affirmations
The mother demonstrates (either verbally or nonverbally): the way a game should be played by showing the child how to "play;" or by bringing a new toy into play, as a way to increase the child's playing options.

*"You stand over there and I will kick it to you."

*"Put your hands out like this."

*"Do you want to call somebody up?"

*"Do you want to give those guys a ride in the cozy coupe."

*Mother demonstrates the noise that a fire engine makes while driving it around.

*"Can I put this fireman in the back of the truck?"

*"Make the truck go to that burning use."

*"Pour me some tea from the tea pot, please."

The mother affirms the child's behavior through the use of affirming words or through nonverbal gestures.

*"Good job."

*"Yes, that's right."

*Mother claps, nods, smiles, or laughs following child's behavior

*"Good idea."

*"Good catch."

*"Thank you." 


\section{Options-Limiting}

Corrections/

Object Replacements
The mother corrects the child's behavior by showing disapproval either verbally or or through nonverbal gestures. One way in which the mother can correct the child's behavior is by correcting the way a game is being played by the child or by placing the toy in it's "correct position."

*Mother takes fire truck out of child's hands and puts it together.

* Mother places the cups with the same color saucer after the child has placed them haphazardly.

*Mother shakes her head is disapproval.

*Mother frowns.

*Mother tells the child to pay attention to her.

*"Next time throw the ball to me and not the window."

*"No, I want to build it this way."

*"We can't do that here."

*"No, that's not the teapot."

*"No, that's the blue cup. I asked for the green cup."

Note: Choice Construction model adapted from Harding et al. (in press, 1996, 1995). Options-Promoting and Options-Limiting model derived from Stilson and Harding (in press) and Stilson (1993). 
APPENDIX D

TODDLER PLAY LEVELS CODING EXAMPLES 


\section{TODDLER PLAY LEVELS CODING EXAMPLES}

Play Level

Definition

Nonsymbolic

1. Unitary Functional Activity Production of an effect that is unique to single object

*squeeze foam ball

*bounce ball

*play catch

*dial phone

2. Inappropriate combinatorial Inappropriate juxtaposition of two or more objects

* put ball in vehicle

*child tries to get into cozy coupe

3. Appropriate combinatorial Appropriate juxtaposition of two or more objects

*put lid on teapot

*building blocks

*lay out tea party

*stacking plates

*putting tea set back in container

4. Transitional play

Approximation of pretense but without confirmatory evidence *place spoon in cup, no stirring) *talking about garage -- on way to building it

*hand in puppet without talking *hold doll without talking, crying, feeding, etc.

\section{Symbolic}

5. Self-directed pretense

Clear pretense activity *eat from spoon or cup *pretend to go to sleep 
6. Other-directed pretense

\section{Sequential pretense}

\section{Substitution pretense}

Clear pretense activity directed toward other

*kiss, feed, or hug doll

*making puppets talk

*ask mother to play

*act out story

*car makes sound

*moving car to go somewhere

*putting man in the truck

*phone rings

*hands cup to mother (to drink)

Linking two or more pretense actions

${ }^{*}$ feed doll and wipe mouth with sponge)

*driving car into garage

* driving car to house

*burning house and fire truck

*putting cars on dump truck

*dialing, speaking with appropriate piece to ear

$* 2$ dolls/puppets talking

*putting phone to doll

*doll on ladder

* puppet talks to mom

*involved in acting out a story

Pretense activity involving one or more object substitutions

*pretend block is sponge and scrub floor)

*fork as microphone

*block as oranges

*put out fire with hands as hose

*label blocks as something (speaker)

Tamis-LeMonda, C. S. \& Bornstein, M. H. (1994). Specificity in mothertoddler language-play relations across the second year. Developmental Psychology, $\underline{30}(2), 283-292$. 
APPENDIX E

TODDLER PLAY LEVELS CODING FORM 
TODDLER PLAY LEVELS CODING FORM

Subject \#:

Date of Tape:

DOB:

Age:

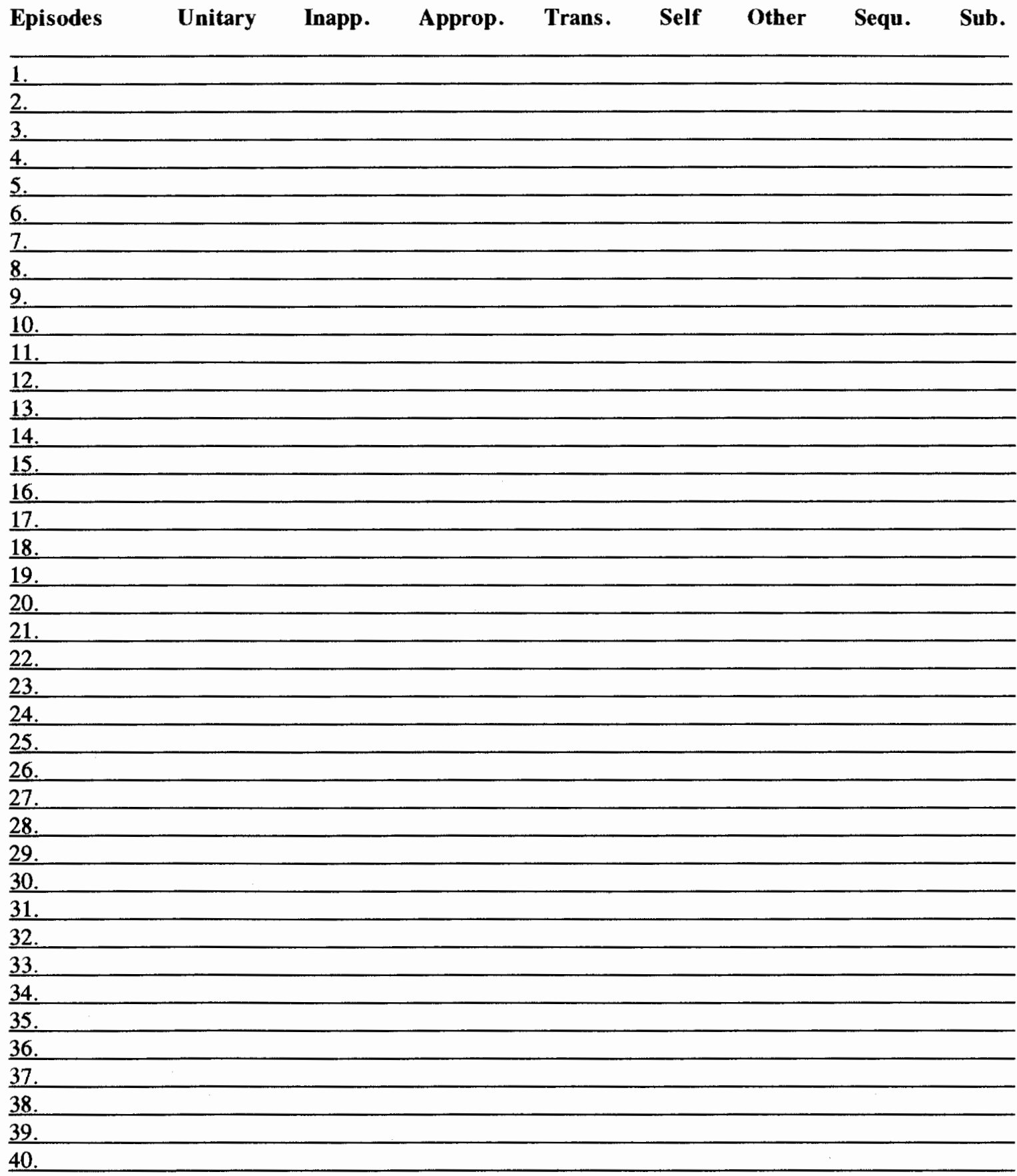




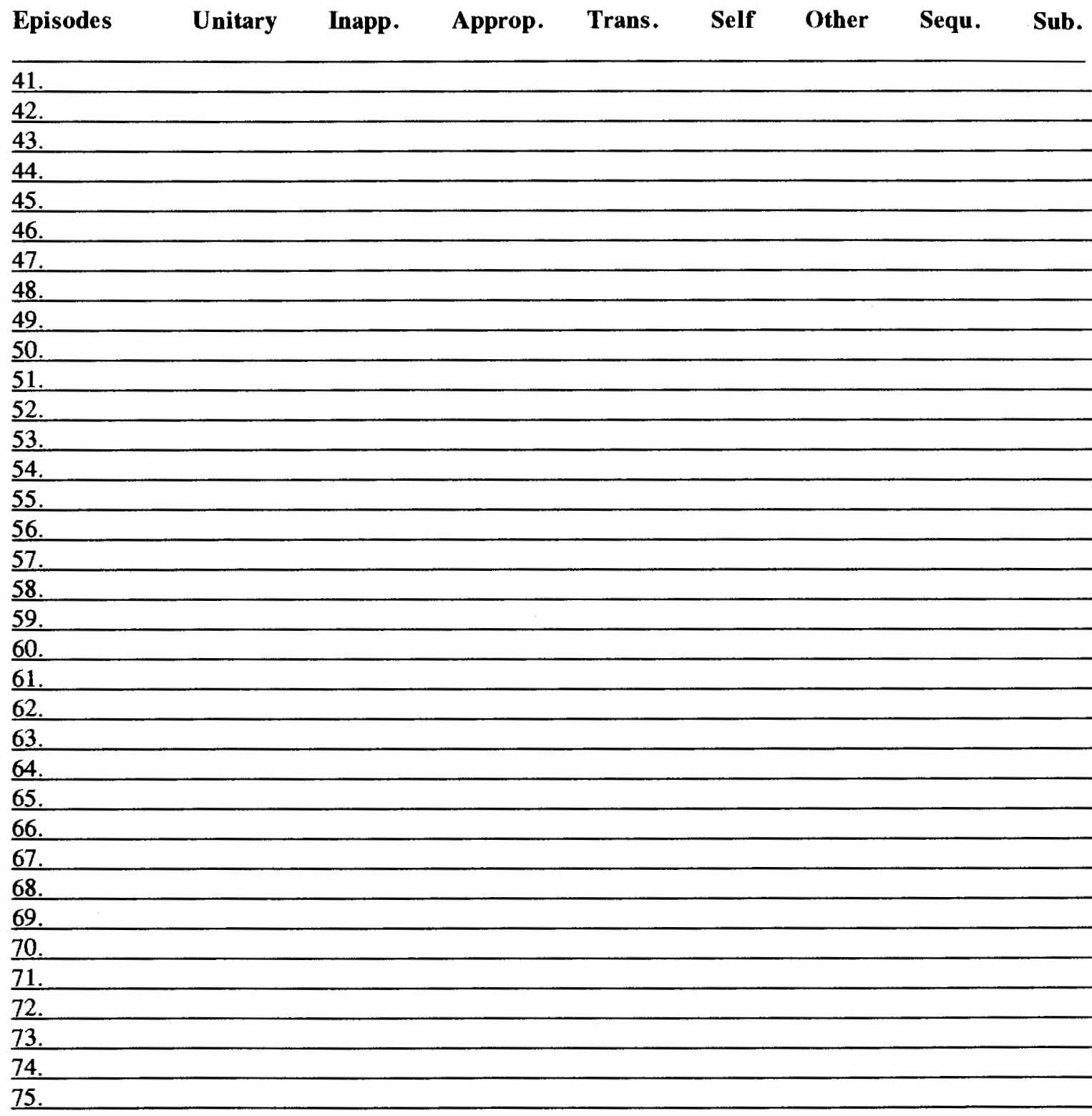

Total: 
APPENDIX F

SYMBOLIC PLAY AND OBLIGATION CHOICE CO-CONSTRUCTION SUMMARY SHEET 


\section{SYMBOLIC PLAY AND OBLIGATION CHOICE CO-CONSTRUCTION SUMMARY SHEET}

Subject \#

Date of Taping

Age

Coder

Toddler Play Levels

Nonsymbolic Play

Unitary Functional Play

Inappropriate Combinatorial

Appropriate Combinatorial

Transitional Play

Total

Symbolic Play

Self-directed Pretense Other-directed Pretense

Sequential

Substitution

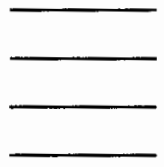

Total

Obligation Choice Co-Construction

Options-promoting

Demonstrations

Affirmations

Total

Options-limiting

Corrections 


\section{REFERENCES}

Bornstein, M.H., Vibbert, M., Tal, J., \& O’Donnell, K. (1992). Toddler language and play in the second year: Stability, covariation and influences of parenting. First Language, 12, 323-338.

Bretherton, I. (1984). Replicating the social world in symbolic play: Reality and fantasy. In I. Bretherton (Ed.), Symbolic play (pp. 1-41). New York: Academic Press.

Bruner, J.S. (1975). From communication to language: A psychological perspective. Cognition, 3(3), 255-287.

Clark, R., Musick, J., Stott, F., \& Klehr, K. (1985). The parent-child early relational assessment. University of Wisconsin.

Clarke-Stewart, K.A. (1973). Interactions between mothers and their young children: Characteristics and consequences. Monographs of the Society for Research in Child Development, 38(6-7), 917-999.

Clarke-Stewart, K.A., Vanderstoep, L.P., \& Killian, G.A. (1979). Analysis and replication of mother-child relations at two years of age. Child Development, 50(3), 777-793.

Dansky, J.L. (1980). Cognitive consequences of sociodramatic play and exploration training for economically disadvantaged preschoolers. Psychiatry, 20, 47-58.

Dansky, J.L. \& Silverman, I.W. (1973). Effects of play on associative fluency in preschool-aged children. Developmental Psychology, 9, 38-43.

Dunn, J., \& Wooding, P. (1977). Play in the home and its implications for learning. In B. Tizard and D. Harvey (Eds.), The biology of play (pp.45-58). London: Spastics International Medical Publication.

Elder, J.L., \& Pederson, D.R. (1978). Preschool children's use of objects in symbolic play. Child Development, 49, 500-504.

Fiese, B.H. (1990). Playful relationships: A contextual analysis of mother-toddler 
interaction and symbolic play. Child Development, 61, 1648-1656.

Harding, C.G. (1982). The development of the intention to communicate. Human Development, 25, 140-151.

Harding, C.G. (1985). Setting the stage for language acquisition: Communication development in the first year. In R.M. Golinkoff (Ed.), The transition from prelinguistic to linguistic communication. Hillsdale, NJ: Erlbaum.

Harding, C.G. (1987). A developmental model for intervention of dilemmas. Human Development, 30, 282-290.

Harding, C.G., Kromelow, S., Stilson, S., \& Touris, M. (1995). First partnerships: The co-construction of intentional communication. Early Child Development and Care, 3, 19-33.

Harding, C.G., Stilson, S.R., \& Moison, J. (1996). First choices: Parent-child communication as the first context for the development of intention. Manuscript submitted for publication.

Harding, C.G., Weissmann, L., Kromelow, S., \& Stilson, S.R. (in press). Shared minds: How mothers and infants co-construct early patterns of choice within intentional communication partnerships. Infant Mental Health Journal.

Kagan, J. (1983). The emergence of self. Annual Progress in Child Psychiatry and Child Development, 23(4), 5-28.

Kreye, M. (1984). Conceptual organization in the play of preschool children: Effects of meaning, context, and mother-child interaction. In I. Bretherton (Ed.), Symbolic play (pp. 299-336). Orlando, FL: Academic Press.

Levine, J.B. (1988). Play in the context of the family. Journal of Family Psychology, 2(2), 164-187.

Lieberman, J.N. (1965). Playfulness and divergent thinking: An investigation of their relationship at the kindergarten level. Journal of Genetic Psychology, 107, 219-224.

Lowe, M. (1975). Trends in the development of representational play in infants from one to three years: An observational study. Journal of Child Psychology and Psychiatry and Allied Disciplines, 16(1), 33-47.

MacDonald, K., \& Parke, R. (1984). Bridging the gap: Parent-child play interaction and peer interactive competence. Child Development, 55, 1265-1277. 
McCune, L., Dipane, D., Fireoved, R., \& Fleck, M. (1994). Play: A context for mutual regulation within mother-child interaction. In A. Slade \& D.P. Wolf (Eds.), Children at play (148-166). New York, NY: Oxford University Preșs.

McCune-Nicolich, L. (1981). Toward symbolic functioning: Structure of early pretend games and potential parallels with language. Child Development. 52(3), 785-797.

Nicolich, L.M. (1977). Beyond sensorimotor intelligence: Assessment of symbolic maturity through analysis of pretend play. Merrill Palmer Quarterly, 23(2), 8999.

Nowak-Fabrykowski, K. (1992). Symbolism, learning and creativity. Journal of Creative Behavior, 26, 268-272.

Nowak-Fabrykowski, K. (1994). Can symbolic play prepare children for their future? Early Child Development and Care, 102, 63-69,

O'Connell, B., \& Bretherton, I. (1984). Toddler's play, alone and with mother: The role of maternal guidance. In I. Bretherton (Ed.), Symbolic play (pp.337-366). Orlando, FL: Academic Press.

Piaget, J. (1962). Play, dreams, and imitation in Childhood. New York: Norton.

Rocissano, L., \& Yatchmink, Y. (1984). Joint attention in mother-toddler interaction: A study of individual variation. Merrill-Palmer Quarterly, 30(1), 11-31.

Rosenberg, M.B. (1968). Diagnostic teaching. Seattle: Special Child Publications.

Slade, A. (1987a). Quality of attachment and early symbolic play. Developmental Psychology, 23(1), 78-85.

Slade, A. (1987b). A longitudinal study of maternal involvement and symbolic play during the toddler period. Child Development, 58, 367-375.

Small, M.Y. (1990). Cognitive development. New York: Harcourt, Brace Jovanovich, Publishers.

Stilson, S.R. (1993). Infant thinking styles: Mother-infant interactive choice construction and its relationship to symbolic play. Unpublished doctoral dissertation, Loyola University Chicago.

Stilson, S.R., \& Harding, C.G. (in press). Early social context as it relates to symbolic play: A longitudinal investigation. Merrill-Palmer Quarterly. 
Tamis-LeMonda, C.S. \& Bornstein, M.H. (1990). Language, play, and attention at one year. Infant Behavior and Development, 13, 85-98.

Tamis-LeMonda, C.S. \& Bornstein, M.H. (1991). Individual variation, correspondence, stability and change in mother and toddler play. Infant Behavior and Development, 14, 143-162.

Tamis-LeMonda, C.S. \& Bornstein, M.H. (1994). Specificity in mother-toddler language-play relations across the second year. Developmental Psychology, 30(2), 283-292.

Trawick-Smith, J. (1990). The effects of realistic versus non-realistic play materials on young children's symbolic transformations of objects. Journal of Research in Childhood Education, 5(1), 27-36.

Vygotsky, L.S., (1978). Play and its role in the mental development of the child. In J.S. Bruner, A. Jolly, \& K. Sylva (Eds.), Play: It's role in development and evolution. New York: Books.

Weissmann, L. (1987). Interaffectivity in the mother-infant relationship. Unpublished doctoral dissertation, Loyola University Chicago.

Werner, H., \& Kaplan, B. (1963). Symbol formation. New York: Wiley.

Zukow, P.G. (1980). A microanalytic study of the role of the caregiver in the relationship between and language acquisition during the one word period. (Doctoral dissertation, University of California, 1980). Dissertation Abstracts International, 42, 18. 


\section{VITA}

From October 1987 to June 1992, the author, Lisa Michelle Noll attended the University of California San Diego in La Jolla, California. She graduated with a Bachelor of Arts degree with a major in Psychology and a minor in English Literature.

In August 1994, the author entered the Master of Arts program in Community Counseling in the Department of Counseling Psychology at Loyola University Chicago in Chicago, Illinois. The author was awarded a Graduate Tuition Fellowship through the Division of Student Affairs from August 1995 to May 1996. The author was awarded a Graduate Assistantship for the Center for Children, Families, and Community at Loyola University Chicago from May 1996 to August 1996. She has participated in the Center for Children, Families, and Community's research team from January 1995 to the present. She completed the Master of Arts degree in May 1997.

From November 1996 to April 1997, the author worked as a Case Manager II, and from April 1997 to the present as a Staff Therapist I, for the Community Counseling Centers of Chicago SASS program.

From October 1995 to September 1996, the author served as a group cofacilitator for the Baby 'N Me program, affiliated with the Loyola University Chicago Center for Children, Families, and Community. 
From May 1995 to June 1996, the author worked as a Counseling Intern for the Community Counseling Centers of Chicago Child and Family Counseling Center in Chicago, Illinois.

From June 1993 to July 1994, the author worked as a Counselor/Resident Staff for the Mainstream Foundation in Pacific Palisades, California.

From June 1993 to April 1994, the author was a Crisis Line Counselor for the Suicide Prevention Center in Los Angeles, California. 


\section{THESIS APPROVAL SHEET}

The thesis submitted by Lisa Michelle Noll has been read and approved by the following committee:

Carol G. Harding, Ph.D., Director

Professor of Counseling Psychology

Loyola University Chicago

Stephanie R. Stilson, Ph.D.

Lenore Weissmann, Ph.D.

Adjunct Assistant Professor of Counseling Psychology and Pediatrics

Loyola University Chicago

The final copies have been examined by the director of the thesis and the signature which appears below verifies the fact that any necessary changes have been incorporated and that the thesis is now given final approval by the committee with reference to content and form.

The thesis is therefore accepted in partial fulfillment of the requirements for the degree of Master of Arts.

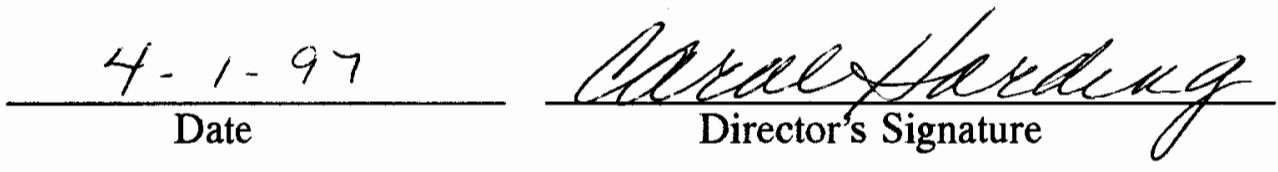

